\title{
HEALTH INSURANCE AND SAVINGS OVER THE LIFE CYCLE - A SEMIPARAMETRIC SMOOTH COEFFICIENT ESTIMATION
}

\author{
SHIN-YI CHOU, ${ }^{\text {a }} *$ JIN-TAN LIU ${ }^{\mathrm{b}}$ AND CLIFF J. HUANG ${ }^{\mathrm{c}}$ \\ a Department of Economics, Lehigh University, USA, and National Bureau of Economics Research, USA \\ b Department of Economics, National Taiwan University, Taiwan, and National Bureau of Economics Research, USA \\ c Department of Economics, Vanderbilt University, USA
}

\begin{abstract}
SUMMARY
Individuals save for future uncertain health care expenses. This is less efficient than pooling health risk through insurance. The provision of comprehensive health insurance may raise welfare by providing the missing market to smooth out consumption through the life cycle. We employ a semiparametric smooth coefficient model to examine the effects of the introduction of the National Health Insurance in Taiwan in 1995 on savings and consumption over the life cycle. The idea is to estimate the coefficients of health insurance which vary with age. Our results suggest that younger households are more sensitive to the risk reductions, and that they demonstrate a greater response in the reduction of their precautionary saving. Copyright (C) 2004 John Wiley \& Sons, Ltd.
\end{abstract}

\section{INTRODUCTION}

Precautionary savings arise when individuals consume less while young, in order to guard against possible income downturns due to uncertain earnings or health expenditure in later life. The availability of health insurance mitigates the risk of uncertain out-of-pocket health expenditure, while reducing the demand for precautionary savings by the households. ${ }^{1}$ Thus, potentially significant welfare gains may be obtained from the implementation of social health insurance programmes by improving risk-sharing mechanisms, and by allocating the resources of households more efficiently over time. While a few studies in the literature have shown evidence of temporary consumption smoothing during periods of unemployment and illness, there is little empirical evidence to support the benefits of social health insurance in terms of consumption smoothing over the life cycle. ${ }^{2}$

The aim of this paper is to assess the potential benefits of social health insurance, by measuring the effect of the programme on consumption smoothing over the life cycle, and in particular assessing the impact of the introduction of National Health Insurance (NHI) in Taiwan in 1995.

\footnotetext{
* Correspondence to: Prof. Shin-Yi Chou, Department of Economics, College of Business and Economics, Lehigh University, 621 Taylor Street, Bethlehem, PA 18015-3117, USA. E-mail: syc2@lehigh.edu

${ }^{1}$ For example, Palumbo (1999) used a dynamic structural model to estimate household consumption decisions during retirement and concluded that uncertain out-of-pocket medical expenses represent an important motive for precautionary savings among the elderly.

${ }^{2}$ For example, Gruber (1997) measured the effect of the unemployment insurance (UI) on consumption smoothing during periods of joblessness and found strong evidence that UI does smooth individual consumption. Gertler and Gruber (2000) found that households in developing countries are not able to fully insure their consumption during periods of illness. Their results suggest larger welfare gains in terms of consumption smoothing from public subsidies for medical care.
} 
Previous works have examined the impact of social or health insurance on savings with the assumption that the effect is constant over the life cycle. For example, based on the simulation results, Kotlikoff (1989) showed that the savings for self-payment exceed those under a fair insurance policy, while savings were smallest in the case of Medicaid. Recent theoretical work by Hubbard et al. (1995) suggested that a significant saving deterrent is associated with means and asset-tested social insurance programmes. Powers (1998) and Gruber and Yelowitz (1999) confirmed this theoretical prediction by showing a strong positive correlation between social insurance eligibility and consumption expenditure. Starr-McCluer (1996) examined the relationship between insurance coverage and wealth, and found a positive effect from health insurance coverage on wealth holdings. Kantor and Fishback (1996) examined the impact of the introduction of insurance against workplace accidents, and found that the existence of workers' compensation led to a reduction in the savings of working households. Engen and Gruber (2001) examined the effects of the unemployment insurance programme on wealth holdings, and found that increasing the generosity of unemployment insurance would lower savings. Chou et al. (2003) have shown that the implementation of National Health Insurance in Taiwan reduced savings by an average of $8.6-13.7 \% .^{3}$

In this paper, we employ a semiparametric smooth coefficient model to examine the different effects of health insurance on precautionary savings through the life cycle. The general idea is to estimate the coefficients of health insurance that vary with age. ${ }^{4}$ The knowledge and understanding of how the health insurance programme impacts differently upon dissimilar age groups has important welfare implications. If the health insurance programme has a greater impact in terms of reducing precautionary savings in younger households, then the welfare gains as a result of consumption smoothing cannot be ignored as a policy consideration.

The resultant regression model is established by using the joint employment status of the household head and his/her spouse. Specifically, we use a natural experiment created by a series of legal changes to examine the effect of $\mathrm{NHI}$ on household savings, and consumption behaviour over the life cycle.

The National Health Insurance programme was officially launched in Taiwan in March 1995. Prior to the implementation of NHI, there were three major health insurance programmes - Labour Insurance, Government Employees' Insurance and Farmers' Health Insurance. ${ }^{5}$ Government employees were the only workers who were able to access health insurance after retirement. Furthermore, only the parents, spouses and children of government employees were family members covered under the insurance policies of government workers. Consequently, the value of NHI-in terms of reducing the risk of catastrophic expenditure-is substantially lower for government-employed households because NHI essentially duplicates the coverage already available through the head (or his/her spouse) of the household. By exploiting the variations in uncertainty with respect to health expenditure prior to the implementation of NHI, we are able to identify the effects of the NHI on household precautionary savings motives over the life cycle.

The complicated and diverse health insurance programmes in Taiwan allow us to infer the effects of the NHI on motives for saving, by comparing the difference in outcomes over time

\footnotetext{
${ }^{3}$ See Deaton (1992) and Browning and Lusardi (1996) for a review.

${ }^{4}$ Amongst the relevant studies, only Engen and Gruber (2001) interact four age group dummies with insurance to determine that the effect of unemployment insurance on precautionary savings falls with age. Their choice of age groups is, however, arbitrary.

${ }^{5}$ See Cheng and Chiang (1997) for a more detailed description of the health insurance programmes in Taiwan.
} 
for a control group, to the difference in outcomes during the same period for a treatment group. This strategy is referred to as a 'difference-in-differences' estimation. ${ }^{6}$ The idea of the difference-in-differences design is that an outcome change for the control group picks up any systematic structural change, while any outcome change in the experimental group reflects both the same systematic structural change, plus the impact of the intervention. In this study, our control group comprises government-employed households, while the experimental group comprises nongovernment-employed households. It is noteworthy that this variation is created by a natural experiment, but does not arise from differences in household behaviours.

We used the Taiwan Survey of Family Income and Expenditure, a nationally representative survey that collects detailed information on the categories of household income and consumption expenditure. In particular, we used a pooled cross-section over eight annual time series to construct aggregated cohort-level data - a pseudo panel—in which households are grouped by their year of birth.

As will be seen in detail in the sections that follow, this study shows that the mitigation of the risk of unexpected medical care expenditure by the NHI programme has the greatest impact, in terms of reducing precautionary savings and increasing consumption, for younger households. These results suggest that the risk-pooling mechanism can help households to both smooth out their consumption and allocate their resources more efficiently.

The structure of this paper is as follows. Section 2 lays out a theoretical framework for consumer maximization, and characterizes the relationship between prudence, the risk of medical expenditure and savings. Section 3 provides background information on the health insurance programmes in Taiwan. Section 4 describes the identification strategy and the data with a graphical presentation of the savings and consumption profile. Section 5 introduces the semiparametric smooth coefficient model. We present the estimation results in Section 6 and subsequently the conclusions are provided in Section 7.

\section{CONCEPTUAL FRAMEWORK}

The central theme of the life-cycle or permanent-income hypothesis, which has sparked volumes of research, is that agents keep the marginal utility of consumption constant over time. Consumption is proportional to the expected present value of lifetime resources. However, if income is stochastic, the closed-form solution can only be obtained under assumptions of quadratic utility function and perfect capital markets. With these assumptions held, the consumption function exhibits the certainty equivalence property: consumption is identical to what would obtain if there were no uncertainty.

In addition, several studies show that imposing a less restrictive assumption on utility function, especially using a utility function which has a positive third derivative, a condition to generate prudent behaviour, will reduce current consumption, and alter the slope of the consumption path. The theoretical condition under which an increase in uninsurable risk leads to more precautionary saving was first derived by Leland (1968) and further analysed by Sandmo (1970) and Drèze and Modigliani (1972). Kimball (1990) defined the concept of 'prudence' and showed that a prudent individual will engage in precautionary savings. Important numerical simulations performed by

\footnotetext{
${ }^{6}$ Similar 'difference-in-differences' estimators have been widely used, for example, by Gruber (1994) and Hamermesh and Trejo (2000). 
Zeldes (1989b) confirmed the theoretical predictions that the consumption function is quite different from the common certainty equivalence benchmark, and suggested that the level of precautionary saving is large. Hubbard et al. (1994) also demonstrated that considering uncertainty regarding the length of life, earnings, and out-of-pocket medical expenditures in the life-cycle model could lead to hump-shaped consumption profiles as households save for precautionary reasons early in life and spend-down these assets during retirement.

Several studies have analysed the case of consumers who are also impatient: households who would like to borrow to finance a high level of current consumption (Zeldes, 1989a; Carroll, 1997; Deaton, 1991). The consumer facing a liquidity constraint may behave similarly to the consumer who can borrow but who has a strong precautionary motive (Carroll, 1997). The existence of a liquidity constraint will strengthen the precautionary motive for saving, and make the consumption path even steeper, since the inability to borrow in a rainy day is another reason to accumulate precautionary assets.

To understand how unexpected health expenditure can influence savings, we consider a stochastic life-cycle model, following Blanchard and Fisher (1989) and Deaton (1992). We do not assume the liquidity constraint in our model. The household is assumed to be uncertain about its future medical expenditure. At each age $t$, a household incurs out-of-pocket health expenditure, $M_{t}$. When $M_{t}$ is known, a household chooses consumption $C_{t}$ and future consumption $\left\{C_{t+1}, \ldots, C_{T-1}\right\}$ to maximize additively time-separable von Neumann-Morgenstern utility. We assume that the utility function exhibits constant and identical absolute risk aversion and absolute prudence. In much the same way as the Arrow-Pratt absolute risk aversion $-U^{\prime \prime} / U^{\prime}$ measures the strength of risk aversion, Kimball (1990) defined absolute prudence as $-U^{\prime \prime \prime} / U^{\prime \prime}$ which measures the strength of the precautionary savings motive. Following Kimball and Mankiw (1989), Caballero (1990) and Weil (1993), the utility function is defined as $U\left(C_{t}\right)=(-1 / \alpha) \exp \left(-\alpha C_{t}\right)$. With the specified utility function, the degree of absolute risk aversion and the degree of absolute prudence are both constant and equal to $\alpha$.

For simplicity, we assume that the discount rate $\delta$ and interest rate $r$ are both equal to zero. Thus, at time zero the household maximizes:

$$
E_{0}\left[\sum_{t=0}^{T-1}\left(-\frac{1}{\alpha}\right) \exp \left(-\alpha C_{t}\right)\right]
$$

subject to

$$
A_{t+1}=A_{t}+Y_{t}-M_{t}-C_{t}
$$

and

$$
M_{t}=M_{t-1}+\varepsilon_{t}, \quad \varepsilon_{t} \sim N\left(0, \sigma^{2}\right)
$$

Health care expenditure is thus modelled as a random walk, with normally distributed error term. Under certain conditions, the optimal consumption level can be solved and simplified to:

$$
C_{t}=\frac{1}{T-t} A_{t}+\left(Y_{t}-M_{t}\right)-\frac{\alpha(T-t-1) \sigma^{2}}{4}
$$

and optimal consumption satisfies:

$$
C_{t+1}=C_{t}+\frac{\alpha \sigma^{2}}{2}+\varepsilon_{t+1}
$$


Equation (4) implies that increases in either uncertainty about future health care expenditures $\left(\sigma^{2}\right)$ or the degree of absolute prudence $(\alpha)$ will yield smaller consumption and greater precautionary savings $\left(=Y_{t}-M_{t}-C_{t}\right)$. Equation (5) shows the effect of uncertain health expenditures on the slope of the consumption path. Higher risk about future health care expenditures $\left(\sigma^{2}\right)$ or higher absolute prudence $(\alpha)$ leads to deferred consumption and results in a steeper consumption path.

The implementation of the NHI programme reduces the risk of unexpected medical expenditure, and thus discourages precautionary savings by the household. If the motive of the household for precautionary saving is strong, the NHI will have a positive welfare effect in terms of consumption smoothing. That is, if $\sigma^{2}$ decreases because of the implementation of NHI, the consumption path in equation (5) will become flatter over time due to the decreases of $C_{t+1}$. This simplified model provides useful insights on the relationship between health insurance and the consumption profile over the life cycle. If $\alpha$ and $\sigma^{2}$ are not functions of age, the reduction in risks (i.e. the reduction of $\sigma^{2}$ ) will shift the consumption profile upward proportionally to $\alpha(T-t-1) / 4$. That is, younger households will increase the consumption level more than older households.

However, the consumption profile over the life cycle after the implementation of NHI may be complicated by the fact that both uncertainty over health expenditure $\left(\sigma^{2}\right)$ and the degree of absolute prudence $(\alpha)$ are functions of age. Kimball $(1990,1993)$ argued convincingly that like risk aversion, prudence also declines with wealth. Individuals who have amassed considerable assets will be less sensitive to potential risks. Given that the wealth profile against age is usually hump-shaped and peaks before the age of retirement in a life-cycle model, the decreasing absolute prudence implies that the NHI will have a stronger effect on the precautionary savings of younger households, and a smaller effect on the households before retirement age. Moreover, households which face a liquidity constraint will also be more sensitive to the risk reduction. If younger households are more likely to face a liquidity constraint, this implies that the NHI will have a stronger impact on their behaviour.

On the other hand, the level of risk reduction induced by the NHI programme will vary across the different age groups. Older people are faced with higher risks from out-of-pocket medical expenditure because of higher morbidity and mortality rates. As a result, the implementation of the NHI programme may provide higher risk reductions among older people, and induce a greater response in terms of reducing their precautionary savings.

Bringing together all of these issues, the response to the NHI, as a function of age, is not uniform. Thus, there is a need for empirical justification of the way in which responses to the risk reductions created by the NHI vary over the life cycle.

\section{BACKGROUND ON NATIONAL HEALTH INSURANCE IN TAIWAN}

Taiwan implemented an NHI plan on March 1, 1995. The implementation of the NHI has dramatically changed how the health care services on the island are financed. Since implementation, the NHI has increased the insured portion of the population from 57\% in 1994 to $97 \%$ in 1998 . Prior to NHI, there were three major health insurance programmes-Government Employees' Insurance (GEI, for government employees), Labour Insurance (LI, for workers and other industrial employees), and Farmers' Health Insurance (FHI, for farmers). ${ }^{7}$ Most of the working population

\footnotetext{
${ }^{7}$ Since 1990, the government provided health insurance for low-income households, but this programme covered less than $1 \%$ of the population. 
was covered by one of these three programmes. In 1992, 37\% of the population was covered under Labour Insurance, 8.2\% under Government Employees' Insurance, and 8.2\% under Farmers' Health Insurance (Peabody et al., 1995; Chiang, 1997). The 47\% of the population who were not covered were mostly children, the elderly, and housewives. GEI was the only plan to cover the spouse, parents and children of the worker. We have excluded farmers from our sample, therefore, the following discussions only focus on LI and GEI.

Labour Insurance was implemented in 1950 and initially designed to cover industrial workers employed in public or private factories. Under the 1970 Labour Insurance Act, employers of journalistic, cultural, non-profit organizations and enterprises with five or more employees were required to insure all workers between the ages of 15 and 60. In 1988, LI was extended to cover public enterprise employees who were not eligible for GEI, and private school teachers and employees. Members of an occupational union who had no definite employer or who were self-employed were also insured under the LI programme. The premium for LI was 6-8\% of monthly-insured salary, $80 \%$ of which was paid by the employer and $20 \%$ by the worker. LI did not provide any health coverage to family members of the workers or employees, nor did it cover retired workers.

Under LI, the patient had to pay a fixed 'registration fee' (NT\$50, US\$1.9) ${ }^{8}$ for each visit. There was no co-payment requirement. About $80 \%$ of hospitals and $47 \%$ of clinics were contracted with this insurance plan. The patients received medical services in these contracted hospitals or clinics (Cheng and Chiang, 1997).

As implemented in 1958, GEI provided mandatory health coverage for government employees. The premium rate was $3-5 \%$ of the government employee's salary, of which $35 \%$ was paid by the employee and $65 \%$ by the government. Eligibility for optional coverage was extended to retired government employees in 1965, and to spouses, parents, and children of government employees in 1982, 1989, and 1992, respectively. GEI had its own health care delivery system. The plan owned six clinical centres in five metropolitan areas and had contracted with $61 \%$ of the hospitals, but less than $6 \%$ of the clinics.

In contrast to previous health insurance programmes, the NHI covers all members of the population. ${ }^{9}$ After the NHI became effective, the administrations for the medical care benefits from the previous social insurance plans (Government Employees' Insurance, Labour Insurance, and Farmers' Insurance) were all transferred to the Bureau of National Health Insurance (BNHI). The BNHI then became the only health insurance provider, incorporating three important features: compulsory universal coverage, uniform comprehensive benefits, and financed through payment of a premium (via payroll deduction) with a heavy governmental subsidy (Chiang, 1997). The GEI, LI and FHI plans continue to administer other types of insurance such as disability, unemployment, and old-age insurance. The absence of a strong private health insurance industry made it politically

\footnotetext{
${ }^{8}$ The average exchange rate was US\$1 $=25.75$ New Taiwan dollars (NT\$) in 1991.

${ }^{9}$ The beneficiary of the NHI includes the insured and his/her dependents. The insured of NHI are classified into the following six categories. 1. Civil servants; employees of publicly or privately owned enterprises or institutions; employees employed by particular employers; employers or self-employed owners of business; independently practicing professionals and technicians. 2. Members of an occupational union; seamen serving on foreign vessels. 3. Members of the Farmers' Association, the Irrigation Association and the Fishers' Association. 4. Dependents of voluntary military officers, noncommissioned officers or servicemen. 5. Members of a household of low-income families. 6. Veterans. The dependents of the insured include: 1 . The insured's spouse who is not employed; 2. The insured's lineal blood ascendants who are not employed; 3 . The insured's lineal blood descendants who are either under 20 years of age and not employed, or are over 20 years of age but incapable of making a living (National Health Insurance Act, Chapter II, Articles 7, 8, 9).
} 
feasible for the government to establish a single social insurance programme. ${ }^{10}$ The NHI benefit includes outpatient care, inpatient care, emergency care, prescription drugs, ambulatory care, emergency care, laboratory tests, mental illness treatment, dental care, and specified preventive care services. ${ }^{11}$ Also the insured are completely free to choose their physicians and hospitals. For outpatient visits, the co-payment ranges from NT\$80 (US\$3.1) to NT\$150 (US\$5.8). For hospitalization, the co-payment ranges from 5\% to 30\% for both acute and chronic care, depending on the length of stay in the hospital. In the case of major illness or injury, no co-payment is required. After implementation of the NHI, the Bureau of National Health Insurance contracted with 785 hospitals and 12,925 clinics, or $97 \%$ of the hospitals and $90 \%$ of the clinics in Taiwan.

Payroll deduction of the premium (payroll tax) is the principal source of financing the NHI. The payroll tax is shared both by the employer and employee. There is a ceiling on the contribution as a percentage of the taxable wage, making the payroll tax in essence a regressive tax. The maximum premium rate is $6 \%$. The ratio of sharing the premium varies among the groups insured. For public employees and their dependents, the insured pay a $40 \%$ share of the premium and the employer (government) pays $60 \%$ of the premium. For private employees and their dependents, the insured pay $30 \%$, the employer pays $60 \%$, and the government subsidizes the remaining $10 \%$ of the premium. ${ }^{12}$ The political party in power does not want to risk its political position by dramatically changing the payroll tax structure; therefore, the financing of the NHI essentially follows the way the LI, GEI and FHI are financed. The other financial sources include lotteries and the tax on tobacco and wine. The government subsidizes about $30 \%$ of the total NHI budget.

The diverse health insurance programmes provide an opportunity to study the effect of health insurance on precautionary saving against unexpected health expenditures. The implementation of the NHI reduces the risk of catastrophic health expenditures and consequently weakens the motive for precautionary saving. We expect that the NHI had a smaller impact on the precautionary savings of government-employed households since their prior coverage was more generous than that of other households, and so the NHI had less effect on reducing uncertainty about medical expenditures. This natural experiment allows us to study precautionary saving without selection bias.

\section{IDENTIFICATION STRATEGY AND DATA}

\subsection{Identification Strategy}

Our estimation strategy compares the change of household consumption, and the saving behaviour of households who had almost identical insurance coverage before and after NHI, to those

\footnotetext{
${ }^{10}$ Private health insurance was small before 1990. In 1994, the market was open to all foreign insurance companies. By 1998, there were 16 domestic and 17 foreign companies operating in the private health insurance market. Liu and Chen (2002) find that there is some degree of complementarity between the social insurance system and private health insurance. The purposes of purchasing private health insurance are: (1) to avoid considerable co-payments in serious illness; (2) to prevent people from financial losses due to catastrophic illness; (3) to receive higher quality services and to bypass the waiting list from an NHI hospital bed to a non-NHI hospital bed.

${ }^{11}$ Expenses arising from the following services are not covered in the NHI: medical service expenses or immunization which should be borne by the government according to other laws or regulations; treatment of drug addiction, cosmetic surgery, non-post-traumatic orthodontic treatment, preventative surgery, artificial reproduction, and sex conversion surgery; over-the-counter drugs and non-prescription drugs; services provided by specially designated doctors and nurses; blood (except for blood transfusion necessary for emergent injury or illness); human-subject clinical trials; hospital day care; food; transportation and registration fee; and dentures, artificial eyes, spectacles, hearing aids, wheelchairs, canes, and other treatment equipment not required for positive therapy.

${ }^{12}$ In 1996, the premium payable ranged from $2 \%$ to $5 \%$ of total household income.
} 
of households who experienced an expansion of insurance coverage to the members of their households after the start of NHI. Prior to the start of NHI, if at least one spouse worked in the government sector, the other spouse, children and parents could be covered under his (or her) extended insurance programme. Thus, the introduction of comprehensive health insurance may have limited impact on those households, because they have almost identical insurance coverage after the start of NHI. Therefore, our control group (government-employed households) consists of households where at least one spouse in a couple works in the public sector. Our treatment group (non-government-employed households) includes households where the head of the household works in the private sector and the spouse is either a non-government employee or not in the labour force or unemployed. Similar definitions of control and treatment groups are employed in Chou and Staiger (2001) and Chou et al. (2003).

\subsection{Data and Sample}

The data used in this analysis are obtained from the Survey of Family Income and Expenditure (SFIE) conducted between 1991 and 1998. Since samples are drawn yearly, it is impossible to track individual households longitudinally. About 13,000 to 16,000 households are surveyed, which provide approximately 52,000 to 68,000 subjects aged 15 years and over for interview each year. The survey contains not only information on demographic characteristics, economic status and industrial sector of employment for each individual in the household, but also the detailed categories of household income and consumption expenditure. Household income includes compensation for all employees among the household members, and includes entrepreneurial, property and transfer income. Total household expenditures include durable, non-durable and other miscellaneous expenditures. ${ }^{13}$ For heads of the household and their spouses, the survey also provides information on their individual wage rates and income.

The data used in the analysis represents a time series of repeated cross-sections, which is different from the panel data normally obtained by following the same households through time. We constructed a pseudo-panel using cohort average, as suggested by Deaton (1985) and Browning et al. (1985), to estimate the model. The main idea behind this synthetic cohort analysis is to provide a means of following the average savings behaviour of homogeneous groups, as they age, over time. Cohorts are defined on the basis of the year of birth of the head of the household. We then averaged the variables of interest over all the households belonging to a given cohort observed in a given year.

The data are sufficiently large to define cohorts for each year of age. Since our sample covers eight years, each cohort overlaps with an adjacent cohort at seven ages. The choice of the interval defining the cohort is arbitrary, involving a trade-off between the interval and the cell size in each cohort. On the one hand, the choice of a narrow interval yields relatively more homogeneous groups; on the other hand, the choice of a larger cell size reduces the sampling noise of the resultant pseudo-panels.

Our sample is restricted to married couples whose household heads were either self-employed, or employed within the public or private sectors. Agricultural families are excluded from the sample. We excluded those industries in the private sector which are not covered by the Labour Standards

\footnotetext{
${ }^{13}$ Specifically, total household expenditures include food, beverages, tobacco, rent (paid or imputed), fuel, household operations, furniture and family facilities, medical care and sanitation, transport and communication, recreation, education and culture, other miscellaneous expenditures, interest and transfer expenditures. 
Law. ${ }^{14}$ Government-employed workers are entitled to receive retirement benefits. However, nongovernment-employed workers can only receive retirement benefits if they worked in industries covered under the Labour Standards Law. ${ }^{15}$ These restrictions and the deletion of households with incomplete information resulted in a working sample of 42,278 non-government-employed households and 9945 government-employed households. Those households whose head was born after 1973 or before 1927 were eliminated from the sample. All the remaining households were allocated to 47 cohorts on the basis of the year of birth of the household head. This procedure would give us 376 ( 47 cohorts $\times 8$ years) observations on cohort-year pairs. We only considered observations with the age of the head of household between 25 and 64 at the survey year. The sample was truncated at age 64 to avoid specifying the bequest function. As a result the pseudo-panel is not balanced. ${ }^{16}$ There are 320 observations on cohort-year pairs for nongovernment-employed households, and 319 for government-employed households. In Table I, we report the cohort definition, their age in 1991, and the average cell size in each cohort.

As noted by Moffitt (1993), Deaton and Paxson (1994), Attanasio and Weber (1995) and Attanasio (1998), the use of synthetic panel techniques has several advantages in the estimation of life-cycle profiles. We are able to follow over time a homogeneous group of individuals born in the same period and therefore coming of age at the same time. It is potentially very misleading to estimate age profiles by pooling together several cross-sections and grouping by age, because of the presence of cohort effects. Moreover, short panel or sample attrition is not an issue in a pseudo-panel.

Table I. Cohort definition

\begin{tabular}{ccccc}
\hline Cohort & Year of birth & $\begin{array}{c}\text { Age in } \\
1991\end{array}$ & $\begin{array}{c}\text { Average cell } \\
\text { size in each } \\
\text { cohort } \\
\text { (government) }\end{array}$ & $\begin{array}{c}\text { Average cell } \\
\text { size in } \\
\text { each cohort } \\
\text { (non-government) }\end{array}$ \\
\hline $1-5$ & $1927-1931$ & $64-60$ & 65 & 169 \\
$6-10$ & $1932-1936$ & $59-55$ & 129 & 319 \\
$11-15$ & $1937-1941$ & $54-50$ & 164 & 599 \\
$16-20$ & $1942-1946$ & $49-45$ & 207 & 806 \\
$21-25$ & $1947-1951$ & $44-40$ & 356 & 1424 \\
$26-30$ & $1952-1956$ & $39-35$ & 411 & 1765 \\
$31-35$ & $1957-1961$ & $34-30$ & 369 & 1068 \\
$36-40$ & $1962-1966$ & $29-25$ & 215 & 314 \\
$41-45$ & $1967-1971$ & $24-20$ & 60 & 62 \\
$46-47$ & $1972-1973$ & $19-18$ & 7 & \\
\hline
\end{tabular}

\footnotetext{
14 The social security system for private workers is governed by two laws: the Labour Insurance Act and the Labour Standards Law, enacted in 1958 and 1984 respectively. A key provision of the Labour Standards Law mandated that employers provide lump-sum retirement and severance benefits. The size of the benefits depended on a worker's tenure with his current employer. Levenson (1996) found that consumption did not increase immediately for those who were granted the retired benefits, relative to those who received no benefits.

${ }_{15}$ The classifications are (i) agriculture, forestry and fishing; (ii) mining and quarrying; (iii) manufacturing; (iv) electricity, gas and water; (v) construction; (vi) transportation, storage and communication; (vii) commerce; (viii) finance, insurance, real estate and business services; and (ix) public administration, social and personal services. The last three were not covered by the Labour Standards Law and are excluded from our sample.

${ }^{16}$ For example, cohort 1 includes those who were born in 1927 and who were 64 years old in 1991. The observations of cohort 1 after 1991 are not included, because their ages were greater than 64 .
} 

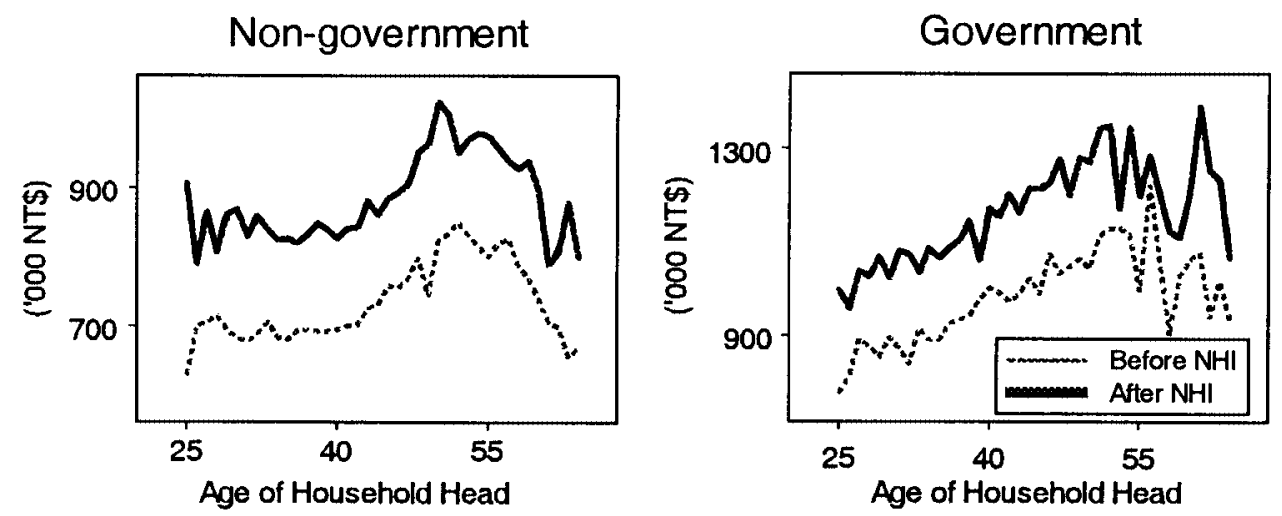

Figure 1. Income over the life cycle

We defined two saving variables for regression analyses. Savings are defined as the difference between household disposable income and household expenditure. The first definition excludes household durables; it adjusts consumption expenditures by adding expenditures on family furniture, furnishing and household equipment, paid or imputed rent and imputed value of the house (either rental value or market value). The second measure adds household durables.

In Figures 1 and 2, we plot average cohort income and consumption (including durable goods and excluding durable goods) against age for non-government-employed and governmentemployed households, respectively. Both income and consumption are hump-shaped for nongovernment-employed households, peaking before retirement age. Income and consumption profiles also demonstrate a hump shape for government-employed households, but both increase around age 61. The shapes of consumption profile are similar regardless of whether the consumption includes durable goods or not. Both consumption and income increased after the implementation of NHI for non-government and government-employed households alike. As discussed in the previous section, the increases in consumption and income for government-employed households will identify the effects of the rapid economic growth in Taiwan through the years. The 'difference-in-differences' between non-government and government-employed households attributes the residual effects to the implementation of the NHI. We consider family composition in Figure 3, and plot the life-cycle profile for consumption per family member. Consumption per household member increases after implementation of the NHI programme for both government and non-government-employed households.

In Figure 4, we plot the average cohort savings against age for non-government and governmentemployed households, respectively. It is worth noting that the NHI programme produced a larger negative impact on the savings of non-government-employed households prior to age 50, whilst having a lesser effect on the savings of older households. This result is consistent with our theoretical argument that the NHI programme reduced the inherent uncertainty of out-of-pocket medical expenditure, and thus reduced the motive for precautionary savings. Younger households are more sensitive to the risks; a result which is consistent with the assumption of decreasing absolute prudence and the existence of liquidity constraint. In contrast, as shown in the righthand panel of Figure 4, NHI did not have any significant impact on the savings profile of government-employed households. Savings increased slightly after the implementation of NHI 
Non-gov. (Inc. Durable Goods)
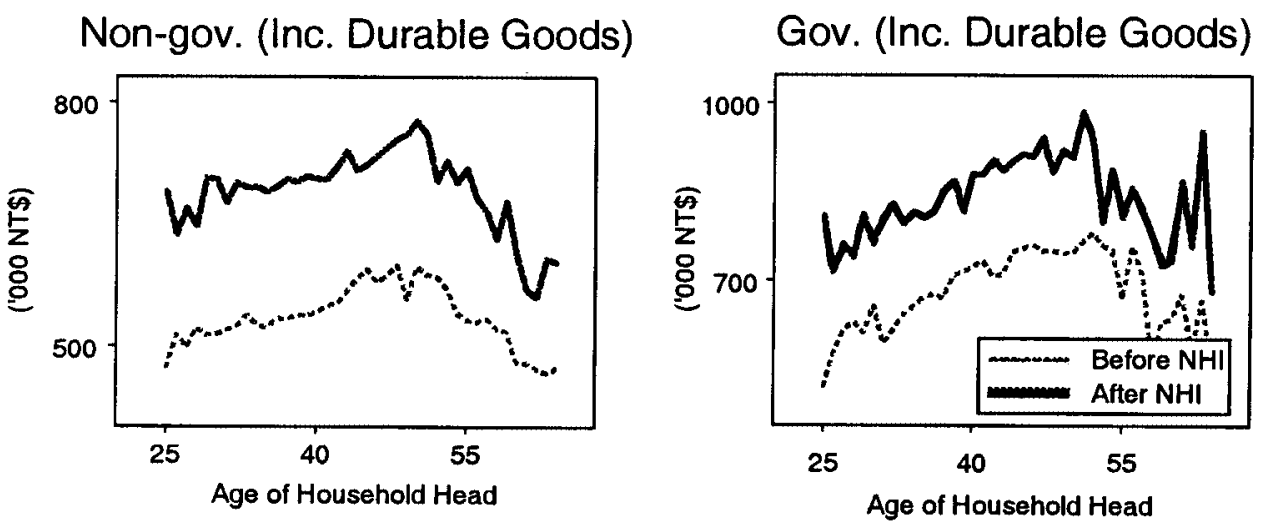

Gov. (Exc. Durable Goods)
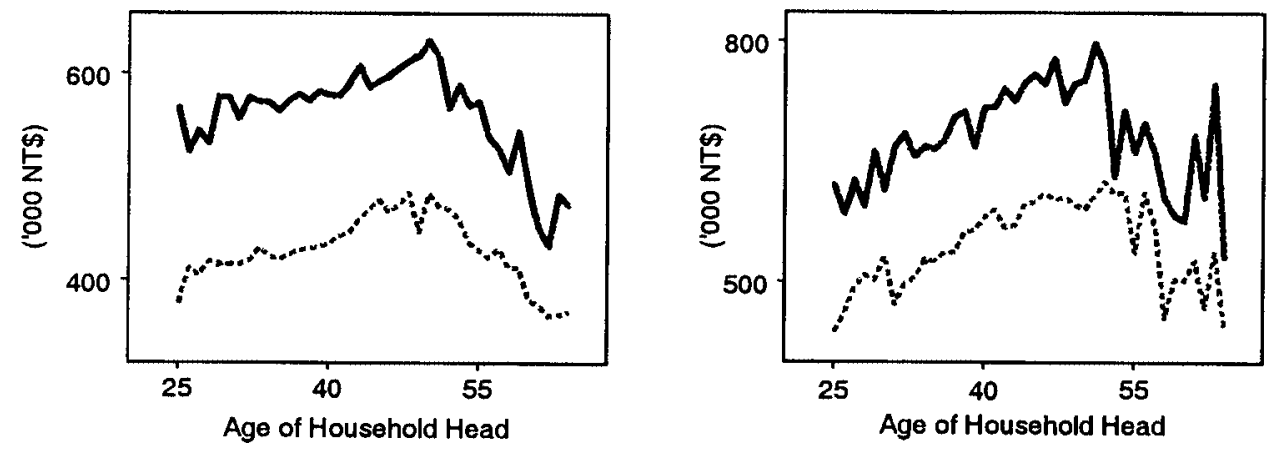

Figure 2. Consumption over the life cycle

for older households, but the change was not significant. This result confirms the supposition that NHI had a smaller effect on the savings of government-employed households, due to the virtually identical insurance benefits both before and after the start of NHI.

\section{EMPIRICAL SPECIFICATION AND A SEMIPARAMETRIC ESTIMATION TECHNIQUE}

\subsection{Difference-in-Differences Estimate}

In order to estimate the effects of $\mathrm{NHI}$ on precautionary savings over the life cycle, we model a varying-coefficient reduced form regression for government $(\mathrm{G})$ and non-government (NG) employed households:

$$
\begin{array}{ll}
\mathrm{G}: & y_{i}=\alpha_{g}\left(A g e_{i}\right)+\beta_{1 g}\left(\mathrm{Age}_{i}\right) N H I_{i}+\beta_{2 g}\left(A g e_{i}\right) I N C_{i}+W_{i}^{\prime} \gamma_{g}+u_{i, g} \\
\mathrm{NG}: & y_{i}=\alpha_{n g}\left(A g e_{i}\right)+\beta_{1 n g}\left(\mathrm{Age}_{i}\right) N H I_{i}+\beta_{2 n g}\left(\mathrm{Age}_{i}\right) I N C_{i}+W_{i}^{\prime} \gamma_{n g}+u_{i, n g}
\end{array}
$$

where $i$ indexes cohort-year and $u$ is a random error term. Dependent variable $y_{i}$ is the average household savings or consumption in each cohort. The all-items Consumer Price Index (CPI) is used to convert all money figures to 1991 New Taiwan dollars (NT\$). The independent 

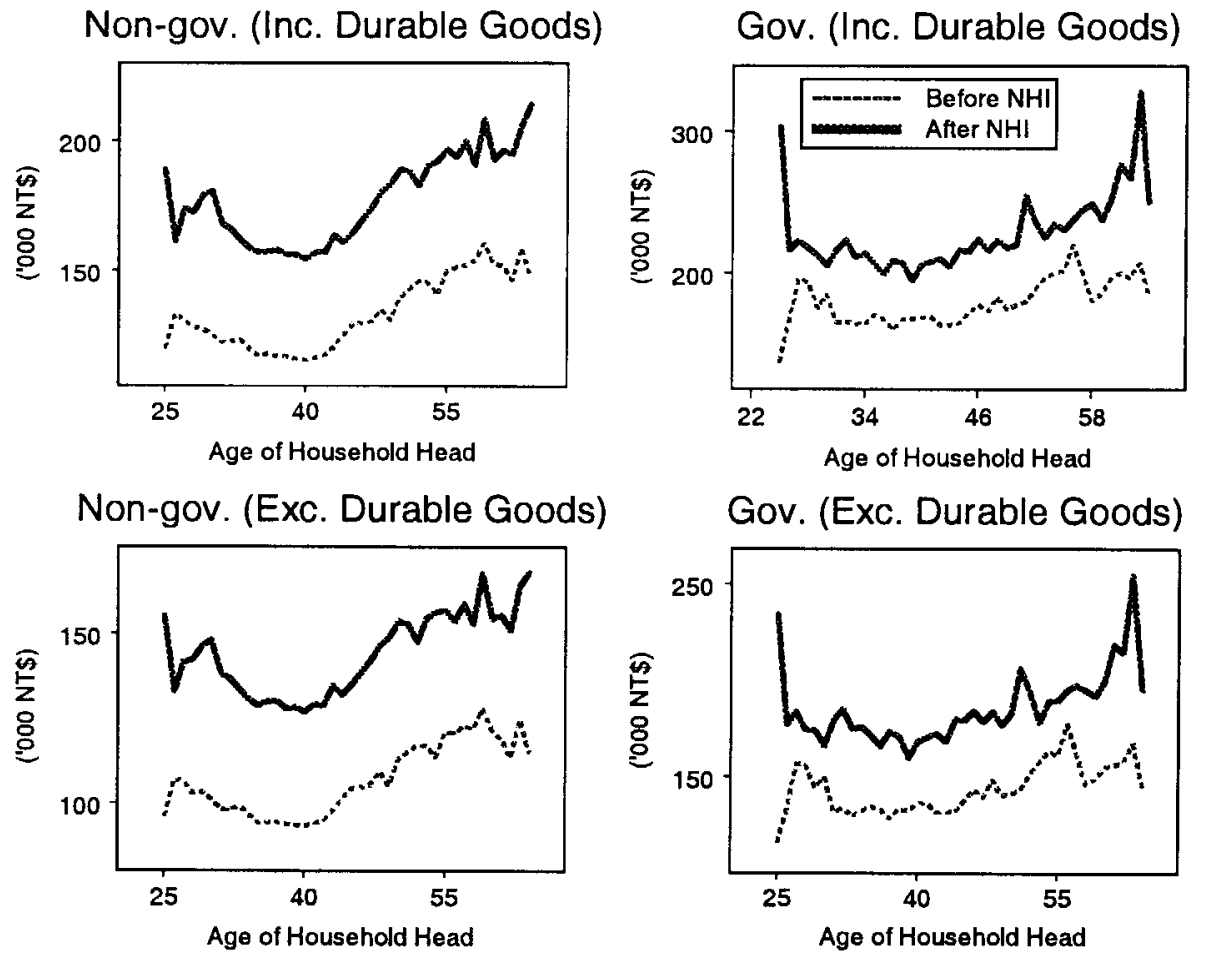

Figure 3. Per capita consumption over the life cycle

variables include an indicator variable $N H I$, household permanent income $I N C$ and a vector $W$ of demographic and financial characteristics of the household head. The indicator $N H I=1$ for the survey years 1995-1998 conducted after the implementation of the NHI programme, and NHI = 0 for the survey years 1991-1994. The vector $W$ includes the education level of the head of the household, family size, and the time trend. The construction of household permanent income is based on the observable characteristics of household head and spouse. Further, it also accounts for the cohort effects. The detailed descriptions are in the appendix.

For both household groups, the savings or consumption profile over the life cycle are modelled via the varying-coefficients of intercept, NHI and INC as functions of Age, i.e., $\alpha(A g e), \beta_{1}(A g e)$ and $\beta_{2}(A g e) .{ }^{17}$ Since the government-employed households had almost identical insurance coverage before and after the implementation of $\mathrm{NHI}$, the estimated coefficient $\hat{\beta}_{1 g}$ (Age) will identify any systematic structural change after 1995. However, the NHI provides better coverage for nongovernment-employed households, as compared to the coverage under the Labour Insurance. Thus, we expect $\hat{\beta}_{1 n g}(\mathrm{Age})$ to be negative for any age group, because the NHI programme reduces the risk of unexpected health expenditures and thus discourages the motives for precautionary savings in the households. The coefficient $\hat{\beta}_{1 n g}(A g e)$ not only picks up the effects of NHI, but may

${ }^{17}$ If households also face uncertainty on their income, it is likely that the marginal propensity to consume will vary with age (Kimball, 1990); thus, $\beta_{2}$ (Age) should also vary with Age. 

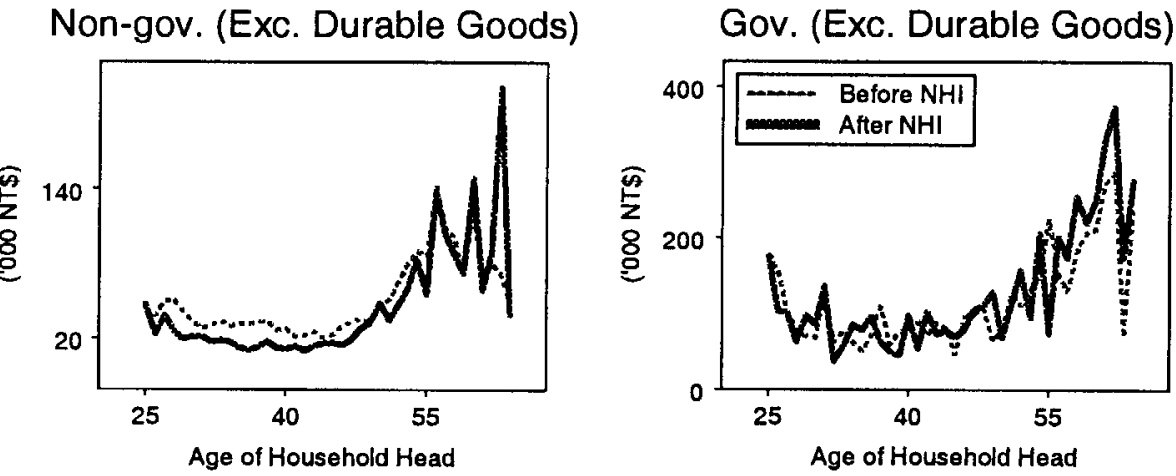

Non-gov. (Inc. Durable Goods)

Gov. (Inc. Durable Goods)
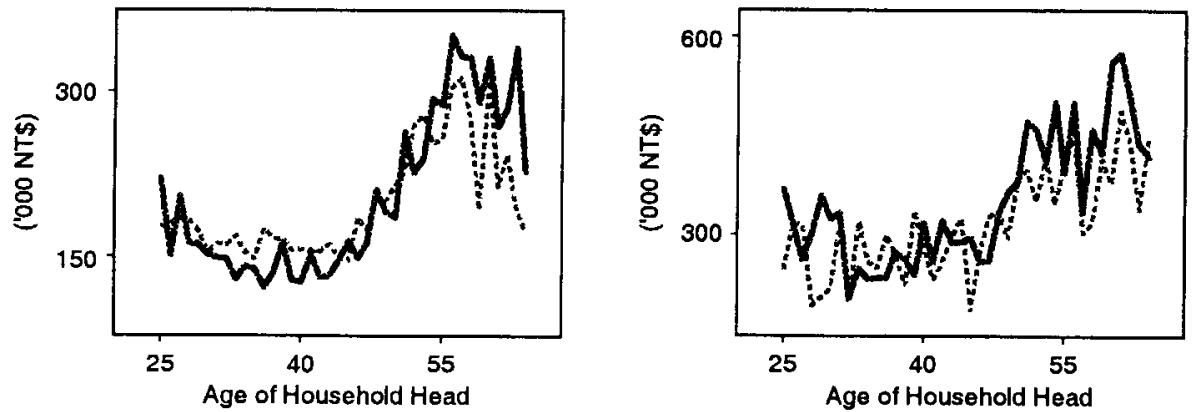

Figure 4. Savings over the life cycle

also identify other structural changes. We therefore employ the 'difference-in-differences' strategy $\left(\hat{\beta}_{1 n g}(A g e)-\hat{\beta}_{1 g}(A g e)\right)$ to isolate the impact of other structural changes.

\subsection{Flexible Parametric Specification-Polynomial in Age}

We first considered a flexible parametric specification to estimate equations (6) and (7). The idea is to specify the varying-coefficients, $\alpha(A g e), \beta_{1}(A g e)$ and $\beta_{2}(A g e)$, as a second-degree polynomial of $A g e .{ }^{18}$ With the group subscripts $g$ and $n g$ suppressed,

$$
\begin{aligned}
& \alpha(\text { Age })=\alpha_{0}+\alpha_{01} \text { Age }+\alpha_{02} A g e^{2} \\
& \beta_{1}(\text { Age })=\beta_{1}+\beta_{11} \text { Age }+\beta_{12} A g e^{2} \\
& \beta_{2}(\text { Age })=\beta_{2}+\beta_{21} \text { Age }+\beta_{22} \text { Age }
\end{aligned}
$$

Thus, the difference-in-differences estimate of the impact of NHI will be the difference in the group estimates

$$
\hat{\beta}_{1 n g}(A g e)-\hat{\beta}_{1 g}(A g e)=\left(\hat{\beta}_{1 n g}+\hat{\beta}_{11 n g} A g e+\hat{\beta}_{12 n g} A g e^{2}\right)-\left(\hat{\beta}_{1 g}+\hat{\beta}_{11 g} A g e+\hat{\beta}_{12 g} A g e^{2}\right)
$$

\footnotetext{
${ }^{18}$ Using a quadratic function in age could substantially reduce the computational complexity. More importantly, based on our theoretical argument the youngest and the oldest households may respond to NHI more significantly; thus, it is legitimate to assume the age polynomial has degree 2 .
} 


\subsection{Semiparametric Specification-Smooth Function of Age}

In order to determine the varying effects of NHI on savings over the life cycle, we consider a more general semiparametric regression model: a semiparametric smooth coefficient model developed by $\mathrm{Li}$ et al. (2002). The main idea is to specify the varying-coefficients, $\alpha(A g e), \beta_{1}(A g e)$ and $\beta_{2}(A g e)$ as unknown, smooth functions of Age. Equations (6) and (7) can be expressed in a more general equation where we drop the subscripts $g$ and $n g$ :

$$
y_{i}=\alpha\left(z_{i}\right)+x_{i}^{\prime} \beta\left(z_{i}\right)+W_{i}^{\prime} \gamma+u_{i} \equiv\left(1, x_{i}^{\prime}, W_{i}^{\prime}\right)\left(\begin{array}{c}
\alpha\left(z_{i}\right) \\
\beta\left(z_{i}\right) \\
\gamma
\end{array}\right)+u_{i} \equiv \chi_{i}^{\prime} \eta\left(z_{i}\right)+u_{i}
$$

where $\chi_{i}=\left(1, x_{i}, W_{i}\right)^{\prime}$ and $\eta\left(z_{i}\right)=\left(\alpha\left(z_{i}\right),\left(\beta\left(z_{i}\right)\right)^{\prime}, \gamma^{\prime}\right)^{\prime}$. The variable $z_{i}$ denotes $A g e_{i}$. The vector $x_{i}$ includes $N H I_{i}$ and $I N C_{i}$, and its coefficient vector $\beta\left(z_{i}\right)$ is a smooth but unknown function of $z_{i}$.

To estimate equation (8) we adopt the three-step process proposed by Li et al. (2002) which showed that $\gamma$ can be consistently estimated at $\sqrt{n}$, while $\beta\left(z_{i}\right)$ can be estimated with the nonparametric rate which is slower than $\sqrt{n}$.

In the first step, all coefficients in (8) are assumed to be smoothing functions of $z$. The regression is then estimated by applying the local least-squares method of Robinson (1989):

$$
\bar{\eta}(z) \equiv\left(\begin{array}{c}
\bar{\alpha}(z) \\
\bar{\beta}(z) \\
\bar{\gamma}(z)
\end{array}\right)=\left[(n h)^{-1} \sum_{j=1}^{n} \chi_{j} \chi_{j}^{\prime} K\left(\frac{z_{j}-z}{h}\right)\right]^{-1}\left[(n h)^{-1} \sum_{j=1}^{n} \chi_{j} y_{j}^{\prime} K\left(\frac{z_{j}-z}{h}\right)\right]
$$

where $K(\cdot)$ is a kernel function and smoothing parameter $h$ is chosen via $h=z_{s d} n^{-1 / 5}$ where $z_{s d}$ is the sample standard deviation of $z$. Unlike equation (8), the estimator $\bar{\gamma}(z)$ in (9) depends on $z$ in the first step, ignoring the fact that the coefficient $\gamma$ is constant.

Subtracting $\bar{\alpha}\left(z_{i}\right)$ and $x_{i}^{\prime} \bar{\beta}\left(z_{i}\right)$ from both sides of (8) yields:

$$
\begin{aligned}
y_{i}-\bar{\alpha}\left(z_{i}\right)-x_{i}^{\prime} \bar{\beta}\left(z_{i}\right) & =W_{i}^{\prime} \gamma+x_{i}^{\prime}\left(\beta\left(z_{i}\right)-\bar{\beta}\left(z_{i}\right)\right)+\left(\alpha\left(z_{i}\right)-\bar{\alpha}\left(z_{i}\right)\right)+u \\
& \equiv W_{i}^{\prime} \gamma+\varepsilon_{i}
\end{aligned}
$$

where $\varepsilon_{i}=x_{i}^{\prime}\left(\beta\left(z_{i}\right)-\bar{\beta}\left(z_{i}\right)\right)+\left(\alpha\left(z_{i}\right)-\bar{\alpha}\left(z_{i}\right)\right)+u_{i}$. Thus, in the second stage of the estimation, a $\sqrt{n}$-consistent estimator of $\gamma$ is obtained by least-squares regression of (10):

$$
\hat{\gamma}=\left(\sum_{i=1}^{n} W_{i} W_{i}^{\prime}\right)^{-1} \sum_{i=1}^{n} W_{i}\left(y_{i}-\bar{\alpha}\left(z_{i}\right)-x_{i}^{\prime} \bar{\beta}\left(z_{i}\right)\right)
$$

The final step is to replace $\gamma$ in (8) with the $\sqrt{n}$-consistent estimator $\hat{\gamma}$ and re-estimate $\alpha(z)$ and $\beta(z)$. Specifically, we subtract $W_{i}^{\prime} \hat{\gamma}$ from both sides of (8) and estimate the equations:

$$
\begin{aligned}
y_{i}-W_{i}^{\prime} \hat{\gamma} & =\alpha\left(z_{i}\right)+x_{i}^{\prime} \beta\left(z_{i}\right)+W_{i}^{\prime}(\gamma-\hat{\gamma})+u_{i} \equiv\left(1, x^{\prime}\right)\left(\begin{array}{c}
\alpha\left(z_{i}\right) \\
\beta\left(z_{i}\right)
\end{array}\right)+v_{i} \\
& \equiv X_{i}^{\prime} \delta\left(z_{i}\right)+v_{i}
\end{aligned}
$$


where $X_{i} \equiv\left(1, x^{\prime}\right)$ and $v_{i}=W_{i}^{\prime}(\gamma-\hat{\gamma})+u_{i}$. The smooth coefficient $\delta(z) \equiv\left(\alpha(z)^{\prime}, \beta(z)^{\prime}\right)^{\prime}$ is estimated by a local least-squares method applied to (12):

$$
\hat{\delta}(z)=\left[D_{n}(z)\right]^{-1} A_{n}(z)
$$

where

$$
\begin{aligned}
& D_{n}(z)=(n h)^{-1} \sum_{j=1}^{n} X_{j} X_{j}^{\prime} K\left(\frac{z_{j}-z}{h}\right) \\
& A_{n}(z)=(n h)^{-1} \sum_{j=1}^{n} X_{j}\left(y_{j}-W_{j}^{\prime} \hat{\gamma}\right) K\left(\frac{z_{j}-z}{h}\right)
\end{aligned}
$$

An iterative procedure of repetition between the second and third stages could be performed. Li et al. (2002) proved that under certain conditions of regularity, the estimators $\hat{\alpha}(z), \hat{\beta}(z)$ and $\hat{\gamma}$ are consistent and asymptotically normally distributed.

Simple test statistics proposed by $\mathrm{Li}$ et al. (2002) can be performed to test the flexible parametric models versus the semiparametric smooth coefficient models. The null hypothesis that the parametric model is a correct specification can be stated as:

$$
\mathrm{H}_{0}: \delta(z)-\delta_{0}(z)=0 \quad \text { almost everywhere }
$$

where $\delta_{0}(z)=\left(\alpha_{0}(z), \beta_{0}(z)^{\prime}, \gamma^{\prime}\right)^{\prime}$ under the flexible parametric model. For example, the flexible parametric specification may be a polynomial in $z, \alpha_{0}(z)=\alpha_{0}+\alpha_{1} z+\alpha_{2} z^{2}$ and $\beta_{0}(z)=\beta_{0}+$ $\beta_{1} z+\beta_{2} z^{2}$. The alternative hypothesis is that the semiparametric model is the correct specification:

$$
\mathrm{H}_{1}: \delta(z)-\delta_{0}(z) \neq 0 \quad \text { on a set with positive measure }
$$

Li et al. (2002) use an integrated squares difference as the basis for the above test. Under certain regularity conditions, the following test statistic $J_{n}$ has the asymptotic standard normal distribution under $\mathrm{H}_{0}$ :

$$
J_{n}=\frac{n h^{1 / 2} \hat{I}_{n}}{\hat{\sigma}_{0}}
$$

where

$$
\begin{aligned}
& \hat{I}_{n}=\left(n^{2} h\right)^{-1} \sum_{i} \sum_{j \neq i} X_{i}^{\prime} X_{j} \hat{\varepsilon}_{i} \hat{\varepsilon}_{j} K\left(\frac{z_{i}-z_{j}}{h}\right) \\
& \hat{\sigma}_{0}^{2}=2(n h)^{-1} \sum_{i} \sum_{j \neq i}\left(\hat{\varepsilon}_{i} \hat{\varepsilon}_{j}\right)^{2}\left(X_{i}^{\prime} X_{j}\right)^{2} K^{2}\left(\frac{z_{i}-z_{j}}{h}\right)
\end{aligned}
$$

and the residual $\hat{\varepsilon}_{i}=Y_{i}-\tilde{\alpha}\left(z_{i}\right)-x_{i}^{\prime} \tilde{\beta}\left(z_{i}\right)-W_{i}^{\prime} \hat{\gamma}$. The residual is obtained from mixed regression, where $\hat{\gamma}$ is the semiparametric estimator of $\gamma$ from (8), whilst $\tilde{\alpha}(z)$ and $\tilde{\beta}(z)$ are the least-squares estimators of the benchmark parametric linear regression. Under the alternative hypothesis $\mathrm{H}_{1}$, the test statistic $J_{n}$ approaches infinity as $n \rightarrow \infty$. Therefore, it is a one-sided test. 


\section{EMPIRICAL RESULTS}

We consider two definitions for consumption and saving in our empirical analyses. The first panel of Table II shows the results for government-employed households. For saving defined as the difference between household disposable income and expenditure while including both durable and non-durable goods (Specification 1), the sample average of $\hat{\beta}_{1 g}(A g e)$ shows a reduction in savings for government-employed households after the implementation of NHI, a $14.5 \%$ reduction based on the semiparametric estimate (Model (2)), which is statistically significant at the $1 \%$ level. ${ }^{19}$ Under flexible parametric specification, the marginal impact of the NHI evaluated at the mean age $\bar{A}(=45.5), \hat{\beta}_{1 g}(\bar{A})=\hat{\beta}_{1 g}+\hat{\beta}_{11 g}(\bar{A})+\hat{\beta}_{12 g}(\bar{A})^{2}$, shows on average a $25.8 \%$ reduction in savings. A more profound reduction in savings after the implementation of NHI is observed for nongovernment-employed households (the second panel of Table II). The estimate $\hat{\beta}_{1 n g}($ Age) shows on average a $55.6 \%$ reduction based on the semiparametric estimate, and a $51.8 \%$ reduction under flexible parametric specification. These reductions in savings may be overestimated. The reductions may be attributable to other systematic structural changes or economic shocks after the implementation of the NHI programme. To isolate these 'nuisance' factors from the true impact of the NHI on household savings, we compute the difference $\left(\hat{\beta}_{1 n g}(A g e)-\hat{\beta}_{1 g}(\right.$ Age $\left.)\right)$. Since the insurance coverage of government-employed households is almost identical, both before and after the introduction of the NHI programme, the estimate $\hat{\beta}_{1 g}($ Age $)$ provides, if any, a measure of the impact of structural changes. Thus the difference-in-differences $\left(\hat{\beta}_{1 n g}(\right.$ Age $)-\hat{\beta}_{1 g}($ Age $\left.)\right)$ estimates the true impact of NHI on savings. The average impact is still considerable at $26.0 \%(=51.8 \%-25.8 \%)$ based on the flexible parametric specification, ${ }^{20}$ and at $41.1 \%(=$ $55.6 \%-14.5 \%$ ) based on the semiparametric estimate, respectively. The difference-in-differences estimate is statistically significant at the $1 \%$ level under the semiparametric specification. ${ }^{21}$ The result is consistent with the theoretical prediction that precautionary savings will decline as a result of the decreased risk from unexpected medical care expenditure.

For saving defined as the difference between household disposable income and expenditure while excluding durable goods (Specification 2), the estimated $\hat{\beta}_{1 g}$ (Age) shows on average a $2.6 \%$ reduction based on the semiparametric estimate for government-employed households. For non-government-employed households, $\hat{\beta}_{1 n g}$ (Age) shows on average a $21.9 \%$ reduction under the semiparametric specification. Under the flexible parametric specification, NHI reduces savings by $9.9 \%$ and $23.2 \%$ for government and non-government-employed households, respectively. The difference-in-differences estimates imply that NHI reduced saving for non-government-employed households by $13.3 \%$ and $19.3 \%$ based on flexible parametric specification and semiparametric estimates, respectively. For semiparametric specification, we also specify the coefficients of the

\footnotetext{
19 The estimated coefficient and $t$-value of the NHI variable shown in Tables II-IV are the sample average of the pointwise estimate. The pointwise individual estimates from (13) and its estimated standard errors are available upon request.

${ }^{20}$ The average impact for flexible parametric specification is calculated as $\hat{\beta}_{1 n g}(\bar{A})-\hat{\beta}_{1 g}(\bar{A})$ where $\bar{A}$ is the average age.

${ }^{21}$ An approximate test for the null hypothesis of no difference in the average of age-varying coefficients for control and treatment groups was used for this analysis. The test statistic is given as $t=d / S_{d}$. The statistic $d=\overline{\hat{\beta}}_{n g}($ Age $)-\overline{\hat{\beta}}_{g}($ Age $)$ is the difference in the average age-varying coefficients, and $S_{d}$ is the standard error of $d$ assuming the independence of $\hat{\beta}_{n g}(A g e)$ and $\hat{\beta}_{g}(A g e)$. That is:
}

$$
S_{d}^{2}=\frac{1}{\left(n_{n g}\right)^{2}} \sum\left[\left(\operatorname{var}\left(\hat{\beta}_{n g}(A g e)\right)\right]+\frac{1}{\left(n_{g}\right)^{2}} \sum\left[\left(\operatorname{var}\left(\hat{\beta}_{g}(\text { Age })\right)\right]\right.\right.
$$

where $n_{i}$ is the number of observations in the $i$ th group and var $(\cdot)$ is the estimated pointwise variance. 
Table II. Estimates of household saving equation (dependent variable: $\log ($ saving))

\begin{tabular}{|c|c|c|c|c|c|c|c|c|}
\hline & \multicolumn{4}{|c|}{$\begin{array}{c}\text { Specification } 1 \\
\text { Saving excludes durable goods }\end{array}$} & \multicolumn{4}{|c|}{$\begin{array}{c}\text { Specification } 2 \\
\text { Saving includes durable goods }\end{array}$} \\
\hline & \multicolumn{2}{|c|}{$\begin{array}{l}\text { Model (1) } \\
\text { polynomial } \\
\text { specification }\end{array}$} & \multicolumn{2}{|c|}{$\begin{array}{c}\text { Model (2) } \\
\text { semiparametric } \\
\text { estimation }\end{array}$} & \multicolumn{2}{|c|}{$\begin{array}{l}\text { Model (1) } \\
\text { polynomial } \\
\text { specification }\end{array}$} & \multicolumn{2}{|c|}{$\begin{array}{l}\text { Model (2) } \\
\text { semiparametric } \\
\text { estimation }\end{array}$} \\
\hline & Coeff. & $t$-Value & Coeff. & $t$-Value & Coeff. & $t$-Value & Coeff. & $t$-Value \\
\hline & \multicolumn{4}{|c|}{$\begin{array}{l}\text { Government-employed households } \\
\qquad(N=319)\end{array}$} & \multicolumn{4}{|c|}{$\begin{array}{l}\text { Government-employed households } \\
\qquad(N=319)\end{array}$} \\
\hline NHI $\left(\hat{\beta}_{1 g}\right)$ & 1.384 & 0.899 & -0.145 & -4.035 & 1.713 & 2.062 & -0.026 & -0.781 \\
\hline Constant & 118.012 & 1.747 & 8.225 & 2.407 & 58.254 & 1.599 & 9.337 & 2.889 \\
\hline Log(permanent income) (INC) & -7.088 & -1.532 & 0.385 & 1.642 & -3.140 & -1.258 & 0.306 & 1.360 \\
\hline Education (year) & -0.061 & -1.033 & -0.159 & -10.323 & 0.001 & 0.039 & -0.094 & -11.130 \\
\hline Family size & 0.015 & 0.100 & -0.227 & -2.549 & 0.089 & 1.090 & -0.026 & -0.531 \\
\hline Time trend & 0.025 & 0.635 & 0.029 & 1.491 & 0.018 & 0.875 & 0.023 & 2.121 \\
\hline Age & -4.958 & -1.505 & & & -1.570 & -0.883 & & \\
\hline $\mathrm{Age}^{2}$ & 0.049 & 1.306 & & & 0.009 & 0.466 & & \\
\hline 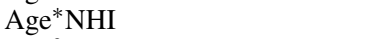 & -0.075 & -1.048 & & & -0.074 & -1.914 & & \\
\hline $\mathrm{Age}^{2 *} \mathrm{NHI}$ & 0.001 & 1.073 & & & 0.001 & 1.732 & & \\
\hline 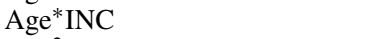 & 0.329 & 1.459 & & & 0.106 & 0.868 & & \\
\hline $\mathrm{Age}^{2 *} \mathrm{INC}$ & -0.003 & -1.254 & & & -0.001 & -0.440 & & \\
\hline Sigma & 0.582 & & 0.598 & & 0.169 & & 0.181 & \\
\hline $\mathrm{R}$-square & 0.204 & & 0.182 & & 0.229 & & 0.176 & \\
\hline \multirow[t]{2}{*}{ Test statistics: $J_{n}$} & 74.701 & & & & 81.361 & & & \\
\hline & \multicolumn{4}{|c|}{$\begin{array}{l}\text { Non-government-employed households } \\
\qquad(N=320)\end{array}$} & \multicolumn{4}{|c|}{$\begin{array}{l}\text { Non-government-employed households } \\
\qquad(N=320)\end{array}$} \\
\hline NHI $\left(\hat{\beta}_{1 n g}\right)$ & -1.104 & -1.129 & -0.556 & -15.964 & -0.087 & -0.174 & -0.219 & -7.434 \\
\hline Constant & -123.210 & -2.752 & -5.311 & -0.312 & -51.380 & -2.229 & -1.188 & -0.170 \\
\hline Log(permanent income) (INC) & 9.926 & 3.155 & 1.342 & 1.148 & 4.621 & 2.851 & 1.019 & 2.134 \\
\hline Education (year) & -0.213 & -4.198 & -0.123 & -7.443 & -0.070 & -2.691 & -0.049 & -5.827 \\
\hline Family size & -0.468 & -2.705 & -1.035 & -17.174 & -0.224 & -2.515 & -0.437 & -14.249 \\
\hline Time trend & -0.016 & -0.614 & -0.010 & -0.780 & 0.013 & 0.952 & 0.017 & 2.758 \\
\hline Age & 6.406 & 2.881 & & & 2.803 & 2.447 & & \\
\hline $\mathrm{Age}^{2}$ & -0.088 & -3.372 & & & -0.038 & -2.868 & & \\
\hline $\mathrm{Age}^{*} \mathrm{NHI}$ & 0.014 & 0.299 & & & -0.014 & -0.600 & & \\
\hline $\mathrm{Age}^{2 *} \mathrm{NHI}$ & 0.000 & -0.016 & & & 0.000 & 0.939 & & \\
\hline 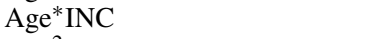 & -0.463 & -2.986 & & & -0.200 & -2.507 & & \\
\hline $\mathrm{Age}^{2 *} \mathrm{INC}$ & 0.006 & 3.465 & & & 0.003 & 2.919 & & \\
\hline Sigma & 0.210 & & 0.222 & & 0.056 & & 0.057 & \\
\hline R-square & 0.669 & & 0.651 & & 0.573 & & 0.561 & \\
\hline Test statistics: $J_{n}$ & 39.088 & & & & 48.742 & & & \\
\hline Effect of NHI $\left(\hat{\beta}_{1 n g}-\hat{\beta}_{1 g}\right)$ & -0.260 & -1.547 & -0.411 & -11.628 & -0.133 & -1.481 & -0.193 & -6.097 \\
\hline
\end{tabular}

constant term and permanent income as functions of age. The 25th, 50th (median) and 75 th percentiles of the estimates based on the semiparametric smooth coefficient model are reported in Table V.

In Table II, the parametric and semiparametric estimations yield similar implications on household savings. By examining the results more closely, however, the parametric results are quite misleading. We first test Model (1) against Model (2). The null hypothesis that Model 
Table III. Estimates of household consumption equation (dependent variable: $\log ($ consumption))

\begin{tabular}{|c|c|c|c|c|c|c|c|c|}
\hline & \multicolumn{4}{|c|}{$\begin{array}{c}\text { Specification } 1 \\
\text { Consumption includes durable goods }\end{array}$} & \multicolumn{4}{|c|}{$\begin{array}{c}\text { Specification } 2 \\
\text { Consumption excludes durable goods }\end{array}$} \\
\hline & \multicolumn{2}{|c|}{$\begin{array}{l}\text { Model (1) } \\
\text { polynomial } \\
\text { specification }\end{array}$} & \multicolumn{2}{|c|}{$\begin{array}{l}\text { Model (2) } \\
\text { semiparametric } \\
\text { estimation }\end{array}$} & \multicolumn{2}{|c|}{$\begin{array}{l}\text { Model (1) } \\
\text { polynomial } \\
\text { specification }\end{array}$} & \multicolumn{2}{|c|}{$\begin{array}{l}\text { Model (2) } \\
\text { semiparametric } \\
\text { estimation }\end{array}$} \\
\hline & Coeff. & $t$-Value & Coeff. & $t$-Value & Coeff. & $t$-Value & Coeff. & $t$-Value \\
\hline & \multicolumn{4}{|c|}{$\begin{array}{l}\text { Government-employed households } \\
\qquad(N=319)\end{array}$} & \multicolumn{4}{|c|}{$\begin{array}{l}\text { Government-employed households } \\
\qquad(N=319)\end{array}$} \\
\hline NHI $\left(\hat{\beta}_{1 g}\right)$ & 0.187 & 1.037 & 0.028 & 3.433 & 0.008 & 0.040 & 0.036 & 2.610 \\
\hline Constant & -2.685 & -0.339 & 5.746 & 20.572 & -2.058 & -0.252 & 5.682 & 10.890 \\
\hline Log(permanent income) (INC) & 1.053 & 1.940 & 0.515 & 26.055 & 1.005 & 1.797 & 0.501 & 13.773 \\
\hline Education (year) & 0.014 & 2.031 & -0.007 & -3.863 & 0.012 & 1.615 & -0.007 & -3.846 \\
\hline Family size & 0.068 & 3.812 & 0.055 & 5.298 & 0.090 & 4.957 & 0.077 & 7.294 \\
\hline Time trend & 0.035 & 7.794 & 0.035 & 15.342 & 0.039 & 8.389 & 0.038 & 16.254 \\
\hline Age & 0.553 & 1.432 & & & 0.530 & 1.332 & & \\
\hline $\mathrm{Age}^{2}$ & -0.007 & -1.646 & & & -0.007 & -1.595 & & \\
\hline Age*NHI $^{*}$ & -0.006 & -0.715 & & & 0.003 & 0.395 & & \\
\hline $\mathrm{Age}^{2 *} \mathrm{NHI}$ & 0.000 & 0.557 & & & 0.000 & -0.630 & & \\
\hline 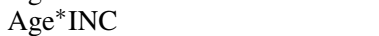 & -0.037 & -1.405 & & & -0.036 & -1.325 & & \\
\hline $\mathrm{Age}^{2 *} \mathrm{INC}$ & 0.000 & 1.628 & & & 0.000 & 1.596 & & \\
\hline Sigma & 0.008 & & 0.008 & & 0.008 & & 0.008 & \\
\hline $\mathrm{R}$-square & 0.734 & & 0.732 & & 0.746 & & 0.747 & \\
\hline \multirow[t]{2}{*}{ Test statistics: $J_{n}$} & 81.027 & & & & 79.503 & & & \\
\hline & \multicolumn{4}{|c|}{$\begin{array}{l}\text { Non-government-employed households } \\
\qquad(N=320)\end{array}$} & \multicolumn{4}{|c|}{$\begin{array}{l}\text { Non-government-employed households } \\
\qquad(N=320)\end{array}$} \\
\hline NHI $\left(\hat{\beta}_{1 n g}\right)$ & 0.393 & 3.519 & 0.041 & 2.472 & 0.394 & 3.482 & 0.055 & 2.325 \\
\hline Constant & 34.732 & 6.795 & 8.112 & 5.889 & 32.901 & 6.350 & 7.903 & 4.895 \\
\hline Log(permanent income) (INC) & -1.563 & -4.350 & 0.334 & 3.509 & -1.444 & -3.965 & 0.330 & 2.960 \\
\hline Education (year) & 0.020 & 3.494 & -0.002 & -1.130 & 0.015 & 2.592 & -0.002 & -1.291 \\
\hline Family size & 0.061 & 3.101 & 0.066 & 9.618 & 0.077 & 3.861 & 0.084 & 12.103 \\
\hline Time trend & 0.048 & 15.620 & 0.048 & 34.036 & 0.048 & 15.582 & 0.048 & 34.312 \\
\hline Age & -1.078 & -4.245 & & & -1.013 & -3.935 & & \\
\hline $\mathrm{Age}^{2}$ & 0.010 & 3.500 & & & 0.010 & 3.206 & & \\
\hline Age*NHI $^{*}$ & -0.015 & -2.818 & & & -0.013 & -2.517 & & \\
\hline $\mathrm{Age}^{2 *} \mathrm{NHI}$ & 0.000 & 2.422 & & & 0.000 & 1.991 & & \\
\hline Age* INC & 0.076 & 4.303 & & & 0.071 & 3.980 & & \\
\hline $\mathrm{Age}^{2 *} \mathrm{INC}$ & -0.001 & -3.553 & & & -0.001 & -3.249 & & \\
\hline Sigma & 0.003 & & 0.003 & & 0.003 & & 0.003 & \\
\hline $\mathrm{R}$-square & 0.900 & & 0.894 & & 0.907 & & 0.904 & \\
\hline Test statistics: $J_{n}$ & 79.191 & & & & 75.663 & & & \\
\hline Effect of NHI $\left(\hat{\beta}_{1 n g}-\hat{\beta}_{1 g}\right)$ & -0.004 & -0.167 & 0.014 & 1.053 & -0.003 & -0.144 & 0.019 & 1.018 \\
\hline
\end{tabular}

(1) is true is rejected with the test statistic 74.7 for government-employed households under Specification 1, which is statistically significant at the $1 \%$ level. The null hypothesis is also rejected for non-government-employed households at the $1 \%$ level under both Specifications 1 and 2.

Since the semiparametric estimators of the smooth coefficients are functions of age, we plot the estimation results and $90 \%$ bounds for both government and non-government-employed households 
Table IV. Estimates of household per capita consumption equation (dependent variable: $\log ($ per capita consumption))

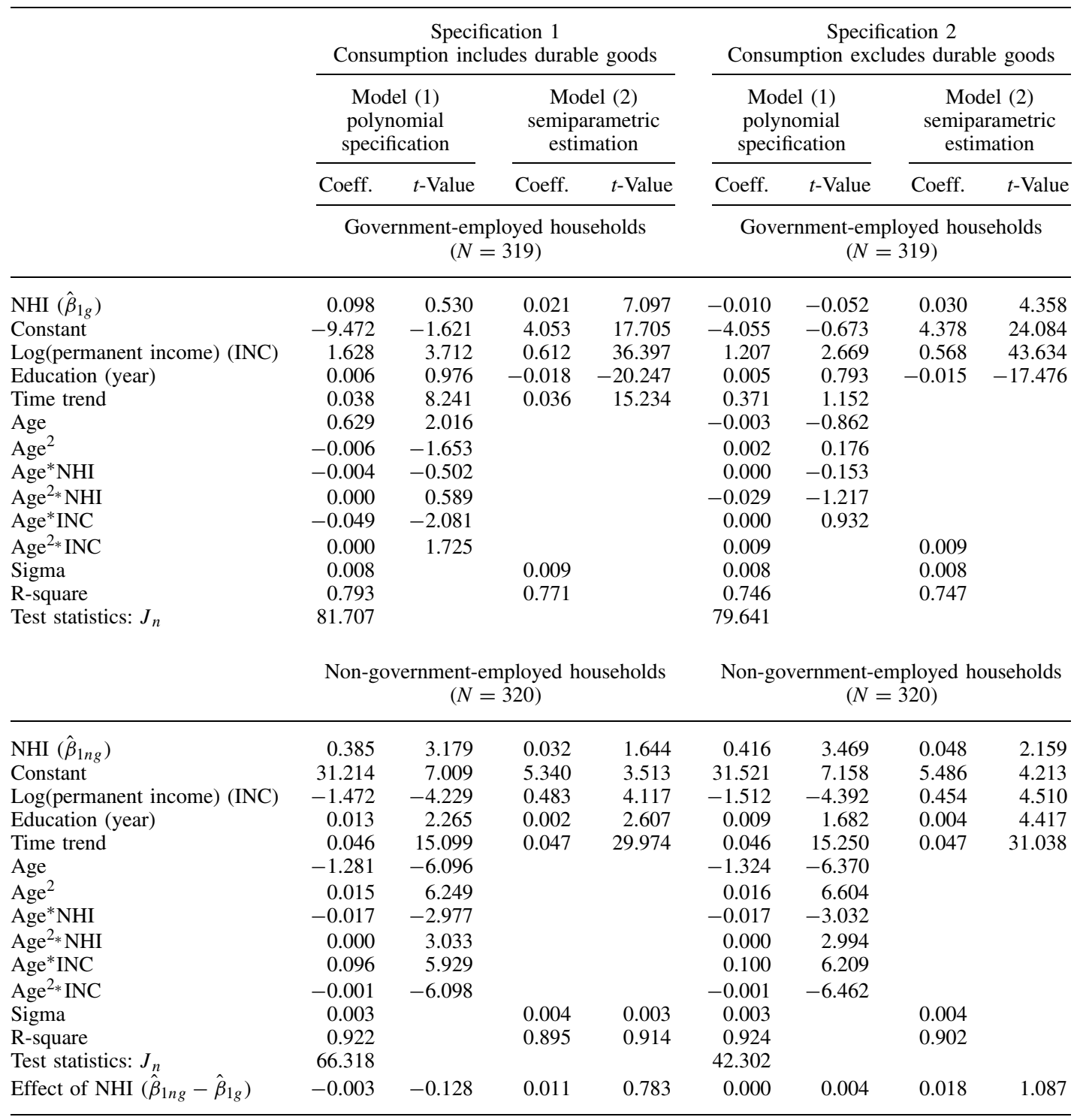

in Figure 5. For comparison, we also plot their corresponding flexible parametric estimation results. For non-government-employed households (Panel A-1 of Figure 5), the flexible parametric model overestimates the negative effects of NHI before age 40, and underestimates the negative effects after age 40. The flexible parametric estimates lie inside the $90 \%$ bounds for about half of the age range. For government-employed households (Panel A-2 of Figure 5), the flexible parametric model overestimates the impacts between ages 35 and 56. The flexible parametric estimates lie inside the $90 \%$ bounds for all age ranges. 
Table V. Semiparametric estimation

\begin{tabular}{|c|c|c|c|c|c|c|}
\hline & \multicolumn{3}{|c|}{$\begin{array}{l}\text { Government-employed } \\
\text { households }\end{array}$} & \multicolumn{3}{|c|}{$\begin{array}{l}\text { Non-government-employed } \\
\text { households }\end{array}$} \\
\hline & 25 Percentile & Median & 75 Percentile & 25 Percentile & Median & 75 Percentile \\
\hline \multicolumn{7}{|l|}{ Savings } \\
\hline Consumption includes durable goods & 5.299 & 8.147 & 9.004 & -23.268 & -0.040 & 10.939 \\
\hline Constant & -0.179 & -0.152 & -0.120 & -0.593 & -0.557 & -0.534 \\
\hline NHI & 0.343 & 0.396 & 0.561 & 0.202 & 0.852 & 2.430 \\
\hline Income & & & & & & \\
\hline Consumption excludes durable goods & 6.929 & 7.700 & 11.486 & -8.321 & 1.291 & 5.338 \\
\hline Constant & -0.050 & -0.038 & -0.020 & -0.247 & -0.225 & -0.200 \\
\hline NHI & 0.155 & 0.417 & 0.468 & 0.565 & 0.800 & 1.444 \\
\hline Income & 5.299 & 8.147 & 9.004 & -23.268 & -0.040 & 10.939 \\
\hline \multicolumn{7}{|l|}{ Consumption } \\
\hline \multicolumn{7}{|l|}{ Consumption includes durable goods } \\
\hline Constant & 5.504 & 5.857 & 5.957 & 6.590 & 8.039 & 9.399 \\
\hline NHI & 0.020 & 0.025 & 0.034 & 0.024 & 0.040 & 0.056 \\
\hline Income & 0.500 & 0.508 & 0.529 & 0.238 & 0.328 & 0.432 \\
\hline \multicolumn{7}{|l|}{ Consumption excludes durable goods } \\
\hline Constant & 5.177 & 5.739 & 6.153 & 6.129 & 7.905 & 9.423 \\
\hline NHI & 0.022 & 0.036 & 0.049 & 0.031 & 0.055 & 0.077 \\
\hline Income & 0.468 & 0.497 & 0.532 & 0.218 & 0.318 & 0.444 \\
\hline \multicolumn{7}{|l|}{ Per capita consumption } \\
\hline \multicolumn{7}{|l|}{ Consumption includes durable goods } \\
\hline Constant & 4.019 & 4.117 & 4.201 & 4.046 & 4.573 & 6.421 \\
\hline NHI & 0.018 & 0.021 & 0.024 & 0.015 & 0.023 & 0.046 \\
\hline Income & 0.600 & 0.607 & 0.614 & 0.380 & 0.541 & 0.579 \\
\hline \multicolumn{7}{|l|}{ Consumption excludes durable goods } \\
\hline Constant & 4.352 & 4.402 & 4.457 & 4.399 & 4.847 & 6.347 \\
\hline NHI & 0.023 & 0.030 & 0.038 & 0.028 & 0.039 & 0.065 \\
\hline Income & 0.562 & 0.567 & 0.571 & 0.370 & 0.496 & 0.535 \\
\hline
\end{tabular}

In Figure 5 (Panel B-1), the vertical distance between two semiparametric curves, or the difference-in-differences estimate, measures the effect of NHI on savings over the life cycle for non-government-employed households. We plot the semiparametric difference-in-differences estimates in Panel B-2. The response profile increases to age 43 and decreases slightly to age 58 , and then increases again to age 64 . This result suggests that the younger households are more responsive to the reduced risk of unexpected medical care expenditure. Older people have higher risk reductions in medical care expenses, and hence may have higher responses to NHI.

In Figure 6, we plot the estimate against age based on the results of Specification 2 (saving includes durable goods). For non-government-employed households (Panel A-1), the flexible parametric estimates lie inside the $90 \%$ bounds for about two-thirds of the age range. For government-employed households (Panel A-2), two-thirds of the flexible parametric estimates lie inside the bounds. Excluding durable goods from consumption yields a slightly different saving response profile to Figure 5. The responses to the NHI programme (absolute values of the estimated coefficients) decreases with age. Younger households are most sensitive to the risk reduction due to the implementation of the comprehensive health insurance programme.

Both government and non-government-employed households experienced an increase in consumption expenditure after the implementation of NHI under both Specifications 1 and 2 (Table III), where Specification 1 includes durable goods consumption but Specification 2 does not. 

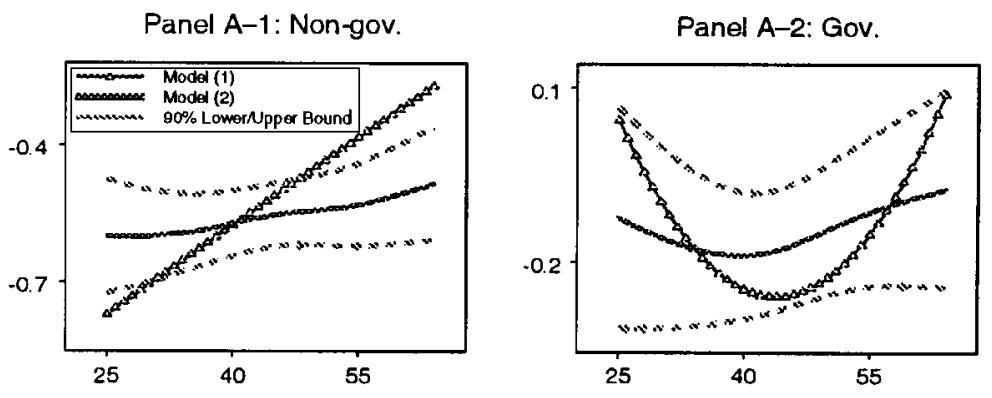

Panel B-1: Semiparametric Est.

Panel B-2: DD Est.
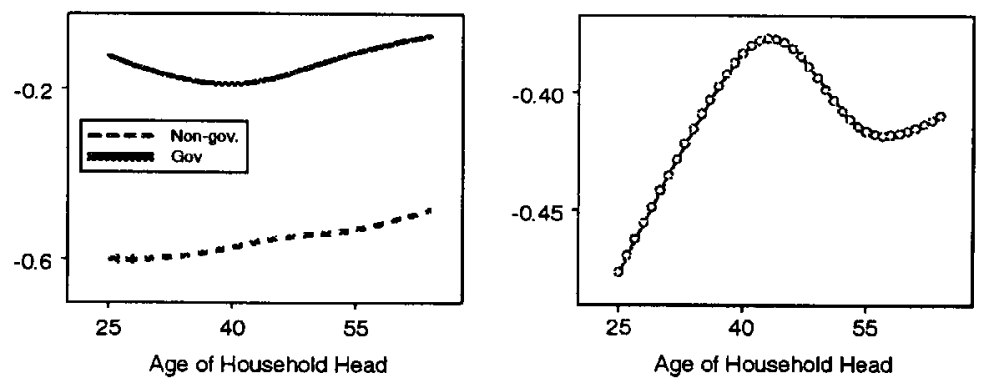

Figure 5. Effects of NHI on savings over the life cycle (saving excludes durable goods)
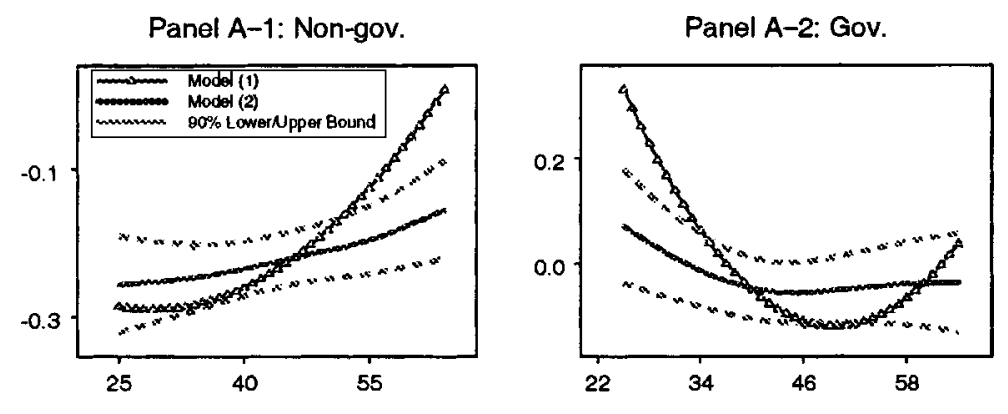

Panel B-1: Semiparametric Est.

Panel B-2: DD Est.
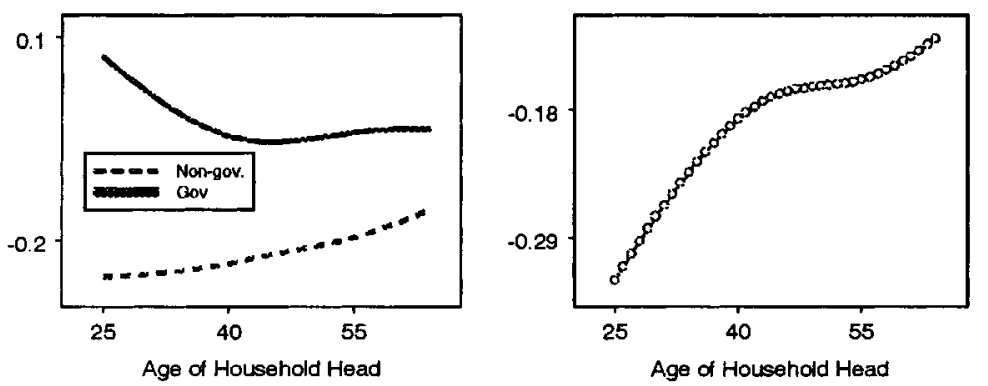

Figure 6. Effects of NHI on savings over the life cycle (saving includes durable goods) 
With consumption including durable goods (Specification 1), under the semiparametric estimation, there is a $2.8 \%$ increase in household consumption for government-employed households after the implementation of $\mathrm{NHI}$, as compared to a $4.1 \%$ increase in household consumption among nongovernment-employed households. The difference-in-differences estimate implies that the NHI increases non-government-employed household consumption expenditure by $1.4 \%$. With consumption excluding durable goods (Specification 2), the semiparametric difference-in-differences estimate implies that the consumption expenditure increases by $1.9 \%(5.5 \%-3.6 \%)$ for nongovernment-employed households after NHI. However, the effects are not statistically significant. The null hypothesis that Model (1) is true is rejected for both government and non-governmentemployed households under both Specifications 1 and 2.

The estimates of the NHI coefficients for consumption are plotted against age variable in Figure 7 (including durable goods) and Figure 8 (excluding durable goods). Flexible parametric estimates (Model (1)) do not lie inside the $90 \%$ bounds for most of the age range for nongovernment-employed households (Panel A-1), but approximate closer to the semiparametric estimates for government-employed households (Panel A-2). In similar fashion to the interpretation in Figures 5 and 6, the vertical distance between the two semiparametric curves measures the effect of NHI on consumption expenditure over the life cycle. The difference-in-differences estimates are shown in Panel B-2. The impact of NHI on consumption decreases with age regardless of the definition of consumption. According to the difference-in-differences estimate, younger households are more sensitive to the implementation of NHI, and consumption expenditures are increased more.

Household consumption expenditure depends inter alia on family size, hence, we also estimate the effect of NHI on per capita household consumption expenditure (Table IV). The

Panel A-1: Non-gov.

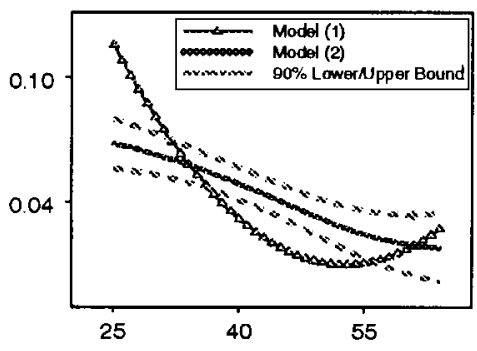

Panel B-1: Semiparametric Est.

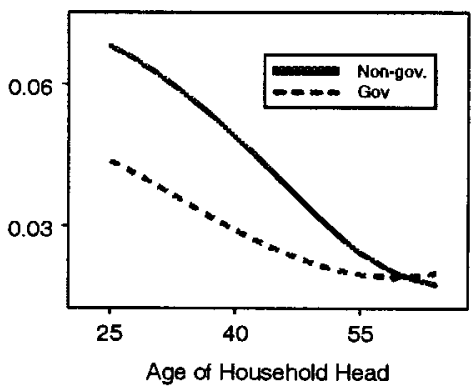

Panel A-2: Gov.

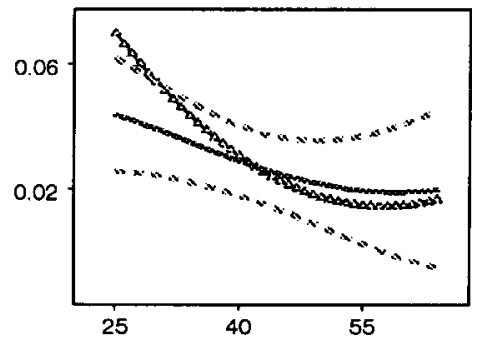

Panel B-2: DD Est.

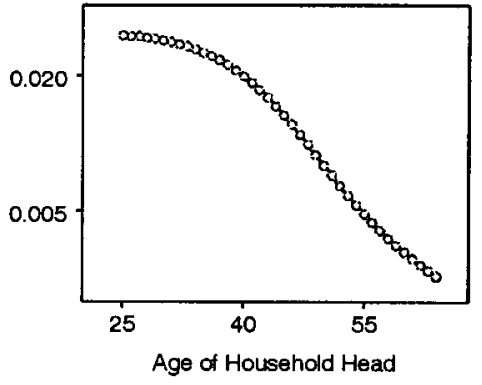

Figure 7. Effects of NHI on consumption over the life cycle (consumption includes durable goods) 
Panel A-1: Non-gov.

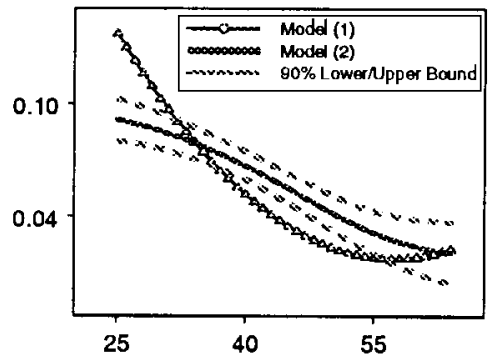

Panel B-1: Semiparametric Est.

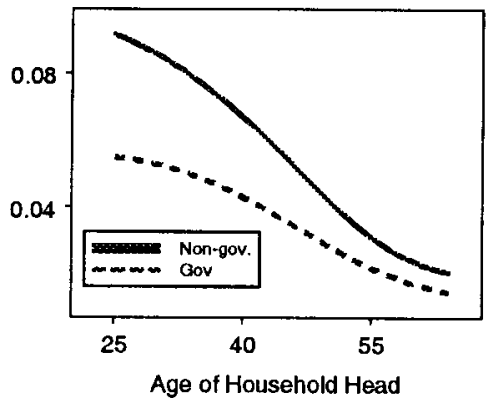

Panel A-2: Gov.

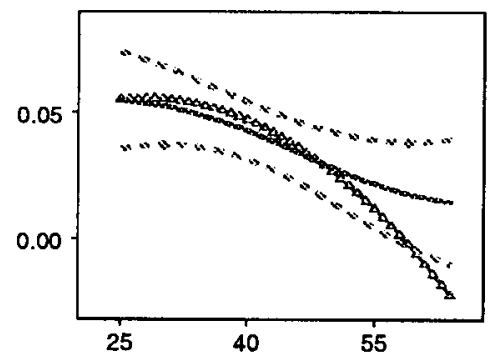

Panel B-2: DD Est.

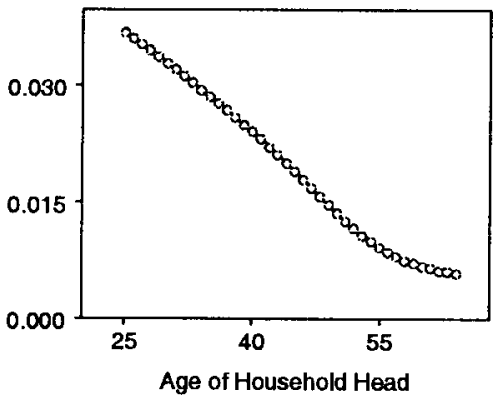

Figure 8. Effects of NHI on consumption over the life cycle (consumption excludes durable goods)

semiparametric difference-in-differences estimates suggest that there were $1.1 \%(=3.2 \%-2.1 \%)$ and $1.8 \%(=4.8 \%-3.0 \%)$ increases per household member in general household consumption expenditure under Specifications 1 and 2, respectively. However, the effects are not statistically significant.

The estimated coefficients under different models and semiparametric difference-in-differences estimates of consumption per household member are plotted in Figures 9 (including durable goods) and 10 (excluding durable goods). Again, flexible parametric estimates are most likely to lie outside the $90 \%$ bound for non-government-employed households (Panel A-1), but perform better for government-employed households. (Panel A-2). The difference-in-differences response profile for consumption is similar when family composition is taken into consideration (Panel B-2). According to the difference-in-differences estimates, the impact of NHI decreases with age. Excluding durable goods (Figure 10) yields a similar response profile.

\section{CONCLUSIONS}

The introduction of social health insurance can substantially reduce the uncertainty surrounding out-of-pocket health expenditure, and thus reduce the motives of households for precautionary savings. Precautionary savings depend both upon the risk of future medical expenses and the household's degree of absolute prudence. If absolute prudence declines with wealth, as suggested by Kimball (1990), younger households will demonstrate a larger response to the risk reduction. 
Panel A-1: Non-gov.

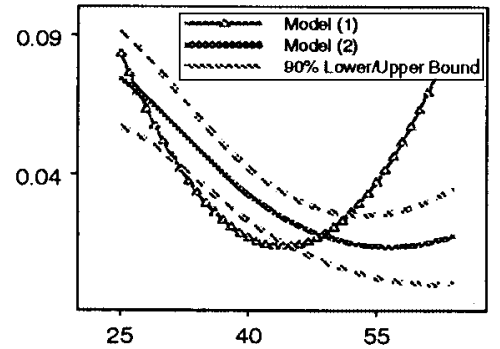

Panel B-1: Semiparametric Est.

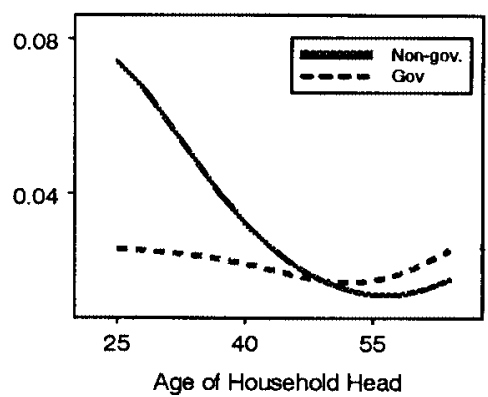

Panel A-2: Gov.

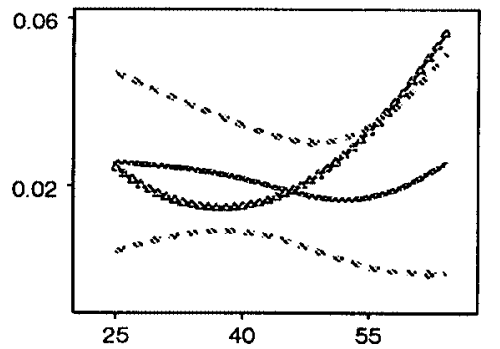

Panel B-2: DD Est.

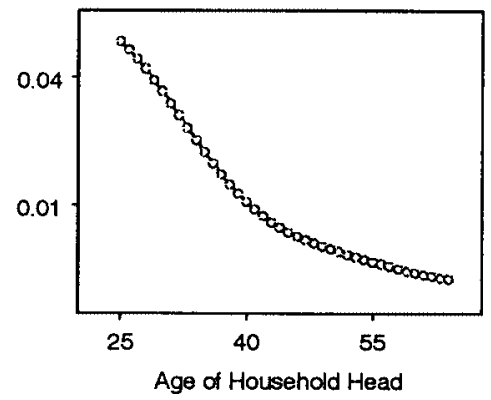

Figure 9. Effects of NHI on per capita consumption over the life cycle (consumption includes durable goods)

However, if the risk of future medical expenses declines substantially for older households with the availability of health insurance, they may display a significant response to this uncertainty change.

When examining the effects of Taiwan's 1995 introduction of the National Health Insurance programme on households' savings and consumption over the life cycle, we find that households reduced their savings and increased their consumption once the comprehensive health insurance became available. Moreover, younger households are more sensitive to the risk reductions and demonstrate a greater response in reducing their precautionary savings. This result is consistent with the theoretical argument of Kimball (1990) and the empirical results of Guiso et al. (1992). Older households (between the age of 58 and 65) also show a greater response in reducing their savings, as compared with other households before retirement age. As predicted in the theoretical argument, one potential reason is that there is a more significant decline in risk for older households.

Rather than numerically solving the Euler equation derived from the dynamic programming model, we employ a semiparametric smooth coefficient model to examine the effects of NHI on savings and consumption over the life cycle. These findings indicate an important welfare implication. Individuals are capable of saving for future uncertain health care expenditure, but this is less efficient than pooling health risk through insurance, since those who do not end up paying their medical bills are inefficiently reducing today's consumption. Furthermore, households trying to smooth out their consumption are faced with potential capital market restraints. Thus, the provision of national health insurance may raise welfare by providing the missing market to smooth out consumption. In particular, children are likely to increase levels of consumption 
Panel A-1: Non-gov.

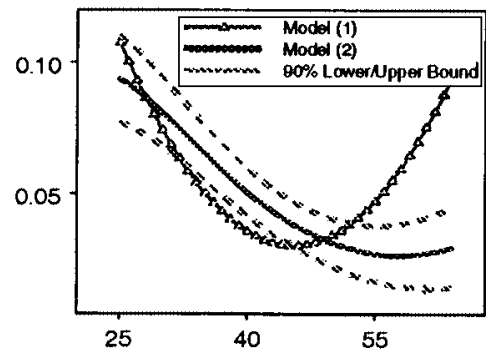

Panel B-1: Semiparametric Est.

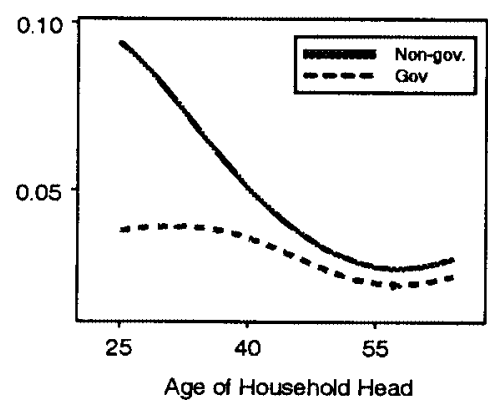

Panel A-2: Gov.

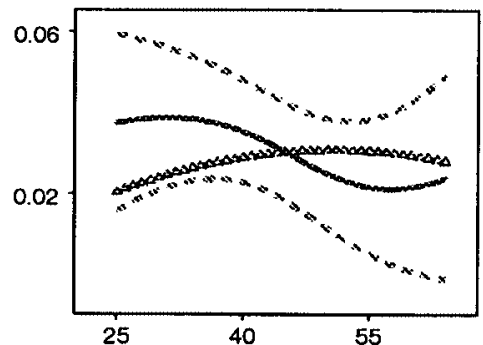

Panel B-2: DD Est.

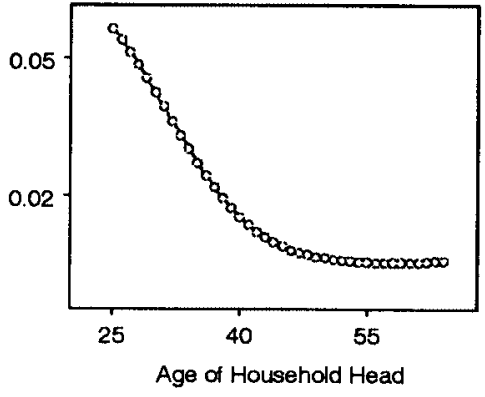

Figure 10. Effects of NHI on per capita consumption over the life cycle (consumption excludes durable goods)

in the middle age range. Through the smoothing mechanism, if households are better able to finance child-rearing and education expenses, the long-term consequences on child development and human capital accumulation may be much more beneficial to society. However, the collective effect of the decrease in savings may lower aggregate capital, output and consumption, and therefore can be potentially welfare reducing. ${ }^{22}$ While this study provides useful information, more research is required to assess the welfare implications and to provide more accurate guidance for policy reform.

\section{APPENDIX: CONSTRUCTION OF PERMANENT EARNINGS}

We follow Guiso et al. (1992) to construct the permanent earnings for heads of a household and their spouses. In brief, the permanent earnings at age $\tau$ can be expressed as

$$
Y(\tau)=Z \beta+\phi(\tau)
$$

where $Z$ is a vector of characteristics for the head of the household and $\phi(\cdot)$ is a quadratic function of age. Assuming 65 years is the maximum age at which people work, the estimated permanent

\footnotetext{
${ }^{22}$ Storesletten, Telmer and Yaron (1999) provided an example that the benefits reduction from savings distortions will outweigh the benefits gains from risk pooling. 
earnings at age $\tau_{0}$ is

$$
Y_{p}\left(\tau_{0}\right)=\left(65-\tau_{0}+1\right)^{-1} \sum_{\tau=\tau_{0}}^{65}[Z b+f(\tau)]\left(\frac{1+n}{1+r}\right)^{\left(\tau-\tau_{0}\right)}
$$

where $b$ and $f$ represent the estimated coefficients of $\beta$ and $\phi$, respectively. Assuming that $r=n$ (i.e. interest rate equals the rate of growth of productivity), the estimated permanent earnings can be calculated as

$$
Y_{p}\left(\tau_{0}\right)=Z b+\left(65-\tau_{0}+1\right)^{-1} \sum_{\tau=\tau_{0}}^{65} f(\tau)
$$

where $f(\tau)$ is the estimated quadratic function of age.

We include demographic characteristics, occupation, sector, regional location and year to estimate $\beta$ and $\phi$. Earnings functions are estimated separately for heads of a household and their spouses. For spouses, we only estimate those who have positive earnings. Permanent income for a household is the sum of the earnings of the head and of the spouse. Estimated results and sample statistics are available upon request.

\section{ACKNOWLEDGEMENTS}

We are grateful to two anonymous referees and the editor, whose comments helped us improve this paper significantly.

\section{REFERENCES}

Attanasio OP. 1998. Cohort analysis of saving behavior by U.S. household. Journal of Human Resources 80: $575-609$.

Attanasio OP, Weber G. 1995. Is consumption growth consistent with intertemporal optimization? Evidence from the Consumer Expenditure Survey. Journal of Political Economy 103: 1121-1157.

Blanchard OJ, Fisher S. 1989. Lectures on Macroeconomics. MIT Press: Cambridge, MA.

Browning M, Lusardi A. 1996. Household saving: micro theories and micro facts. Journal of Economic Literature 34: 1797-1855.

Browning M, Deaton AS, Irish M. 1985. A profitable approach to labor supply and commodity demands over the life cycle. Econometrica 53: 503-543.

Caballero RJ. 1990. Consumption puzzles and precautionary savings. Journal of Monetary Economics 25: $113-136$.

Carroll C. 1997. Buffer-stock saving and the life cycle/permanent income hypothesis. Quarterly Journal of Economics 112: 1-55.

Cheng S-H, Chiang T-L. 1997. The effect of universal health insurance on health care utilization in Taiwan: results from a natural experiment. Journal of the American Medical Association 278: 89-93.

Chiang T-L. 1997. Taiwan's 1995 health care reform. Health Policy 39: 225-239.

Chou S-Y, Liu J-T, Hammitt J. 2003. National health insurance and precautionary savings: evidence from Taiwan. Journal of Public Economics, in press.

Chou Y-J, Staiger D. 2001. Health insurance and female labor supply in Taiwan. Journal of Health Economics 20: $187-211$.

Deaton AS. 1985. Panel data from time series of cross-sections. Journal of Econometrics 30: 109-126.

Deaton AS. 1991. Saving and liquidity constraints. Econometrica 59: 1221-1248.

Deaton AS. 1992. Understanding Consumption. Oxford University Press: New York. 
Deaton AS, Paxson CH. 1994. Intertemporal choice and inequality. Journal of Political Economy 102: 437-467.

Drèze J, Modigliani F. 1972. Consumption decisions under uncertainty. Journal of Economic Theory 5: $308-325$.

Engen EM, Gruber J. 2001. Unemployment insurance and precautionary saving. Journal of Monetary Economics 47: 545-579.

Gertler P, Gruber J. 2002. Insuring consumption against illness. American Economic Review 92: 51-70.

Gruber J. 1994. The incidence of mandated maternity benefits. American Economic Review 84: 622-641.

Gruber J. 1997. The consumption smoothing benefits of unemployment insurance. American Economic Review 87: 192-205.

Gruber J, Yelowitz A. 1999. Public health insurance and private savings. Journal of Political Economy 107: $1249-1274$.

Guiso L, Jappelli T, Terlizzese D. 1992. Earnings uncertainty and precautionary saving. Journal of Monetary Economics 30: 307-337.

Hamermesh DS, Trejo SJ. 2000. The demand for hours of labor: direct evidence from California. Review of Economics and Statistics 82: 38-47.

Hubbard RG, Skinner J, Zeldes SP. 1994. The importance of precautionary motives in explaining individual and aggregate saving. Carnegie-Rochester Conference Series on Public Policy 40: 59-125.

Hubbard RG, Skinner J, Zeldes SP. 1995. Precautionary saving and social insurance. Journal of Political Economy 103: 360-399.

Kantor SE, Fishback PV. 1996. Precautionary saving, insurance, and the origins of workers' compensation. Journal of Political Economy 104: 419-442.

Kimball MS. 1990. Precautionary saving in the small and in the large. Econometrica 58: 53-73.

Kimball MS. 1993. Standard risk aversion. Econometrica 61: 589-611.

Kimball MS, Mankiw NG. 1989. Precautionary saving and the timing of taxes. Journal of Political Economy 97: $863-879$.

Kotlikoff LJ. 1989. Health expenditures and precautionary savings. In: What Determines Savings, Kotlikoff LJ (ed.). MIT Press: Cambridge, MA.

Leland HE. 1968. Saving and uncertainty: the precautionary demand for saving. Quarterly Journal of Economics 82: 465-473.

Levenson AR. 1996. Do consumers respond to future income shocks? Evidence from social security reform in Taiwan. Journal of Public Economics 62: 275-295.

Li Q, Huang CJ, Li D, Fu T-T. 2002. Semiparametric smooth coefficient stochastic frontier models. Journal of Business \& Economic Statistics 20: 412-422.

Liu T-C, Chen C-S. 2002. An analysis of private health insurance purchasing decisions with national health insurance in Taiwan. Social Science \& Medicine 55: 755-774.

Moffitt R. 1993. Identification and estimation of dynamic models with a time series of repeated cross sections. Journal of Econometrics 59: 99-123.

Palumbo MG. 1999. Uncertain medical expenses and precautionary saving: near the end of the life cycle. Review of Economic Studies 66: 395-422.

Peabody JW, Yu JC-I, Wang Y-R, Bickel SR. 1995. Health system reform in the Republic of China. Journal of the American Medical Association 273: 777-781.

Powers ET. 1998. Does means-testing welfare discourage saving? Evidence from a change in AFDC policy in the United States. Journal of Public Economics 68: 33-53.

Robinson PM. 1989. Nonparametric estimation of time-varying parameters. In: Statistical Analysis and Forecasting of Economic Structural Changes, Hackl P (ed.). Springer-Verlag: Berlin.

Sandmo A. 1970. The effect of uncertainty on saving decisions. Review of Economic Studies 37: $353-360$.

Starr-McCluer M. 1996. Health insurance and precautionary saving. American Economic Review 86: $285-295$.

Storesletten K, Telmer CI, Yaron A. 1999. The risk-sharing implications of alternative social security arrangements. Carnegie-Rochester Conference Series on Public Policy 50: 213-259.

Weil P. 1993. Precautionary savings and the permanent income hypothesis. Review of Economic Studies 60: 367-383.

Copyright @ 2004 John Wiley \& Sons, Ltd.

J. Appl. Econ. 19: 295-322 (2004) 
Zeldes SP. 1989a. Consumption and liquidity constraints: an empirical investigation. Journal of Political Economy 97: 305-346.

Zeldes SP. 1989b. Optimal consumption with stochastic income: deviations from certainty equivalence. Quarterly Journal of Economics 104: 275-298. 